\title{
The Elusive Effects of CAFE Standards
}

\author{
Kenneth A. Small \\ University of California at Irvine \\ ksmall@uci.edu
}

August 22, 2017

Keywords: fuel efficiency, CAFE, motor vehicles, energy paradox JEL codes: R48, Q48, L62

\begin{abstract}
Despite decades of empirical assessment, economists have not reached consensus on key impacts of Corporate Average Fuel Economy (CAFE) standards, including how much they reduce fuel consumption. Evaluating CAFE is complicated by factors such as consumers' expectations of future fuel prices, their valuation of and responsiveness to changes in fuel economy, automakers' optimal technological and strategic behavior, changes in used-vehicle markets, and the path of energy prices. I investigate the effects of many of those factors in a quantitative assessment of CAFE. I do so by modifying the U.S. Department of Energy's National Energy Modeling System and using it to simulate variations from a set of reference assumptions. Results are especially sensitive to consumers' valuation of expected fuel cost savings and to the future course of oil prices.
\end{abstract}




\title{
The Elusive Effects of CAFE Standards
}

\author{
Kenneth A. Small
}

\section{Introduction}

Fuel efficiency standards for motor vehicles remain controversial, despite four decades of experience in the United States with its Corporate Average Fuel Economy (CAFE) standards. Economists disagree on the magnitudes of some of the most relevant market responses, ${ }^{1}$ including some-especially the so-called "energy paradox" - that could make standards more efficient than fuel taxes.

This ambiguity is partly due to the complexity of markets for the purchase and use of motor vehicles. While research has led to increasingly sophisticated understanding of consumers' demand for vehicles and of automakers' responses to regulations, it has proved impossible to developed a single framework that fully captures all the relevant aspects such as consumers' perceptions of vehicle attributes, their expectations about fuel prices, manufacturers' decisions about new technologies, consumers' decisions how much to use and when to retire vehicles, and used-vehicle market adjustments.

This paper makes a first step toward a more general model, using a modified version of the U.S. Energy Information Administration's National Energy Modeling System (NEMS). While any large-scale model may omit or over-simplify key economic responses, NEMS is more complete and flexible than single-purpose models and so has the potential to explore the many factors that may be relevant to policy evaluation. One advantage in particular is that it represents in a very detailed way the technologies available to automobile manufacturers for improving fuel efficiency. Furthermore, being a simulation model, it is not restricted by the particular economic specifications and functional forms that may be required by a purely econometric model or by one that seeks to create a comprehensive welfare framework.

For these reasons, I set out to adapt NEMS to estimate the quantitative effects of some of the more important features of an ideal model if it were available. In doing so, I am applying a key

\footnotetext{
${ }^{1}$ See for example Jacobsen (2013), Anderson et al. (2011), Knittel (2012, 2013).
} 
lesson from Theodore Keeler, to whom this paper is dedicated: use practical methods, guided insofar as possibly by sound theory, to search for answers to significant economic questions.

In what follows, I discuss key modeling issues and behavioral parameters in assessing CAFE, and then describe how I specify or modify NEMS to address them. I then construct a baseline scenario and use it to simulate the effects of variations representing different combinations of behavioral and environmental parameters, market responses, and types of standards. I consider how those variations affect the simulated impact of higher CAFE standardsin particular the tightening of CAFE standards to the levels promulgated under the Obama Administration for new vehicles of model years 2017-2025. While I have chosen these standards mainly to test the models, the counterfactual in which they are not imposed (and thus standards remain at the levels previously adopted for 2016) is still policy-relevant as their continuation is subject to a legislatively mandated review, being carried out by an administration with a declared hostility to the standards.

\section{Modeling Issues}

Motor vehicle use involves several interconnected markets. Consumers purchase new and used vehicles, decide how much to drive them, and eventually sell or scrap them. Domestic and foreign automakers design, build, and price vehicles with certain features, including fuel economy. Both vehicles and the investments required to manufacture them are long-lasting, yet consumer preferences and vehicle designs are constantly changing — some year by year, some over few years in advance, and some over many years in advance through research, development, and investment in new technologies. Fuel efficiency standards and other policies affect all of these markets, making it extremely difficult to capture all their effects.

In this section, I discuss several key elements of these markets and how they might be incorporated into models used to evaluate policies.

\subsection{Consumer Behavior and Vehicle Demand}

When consumers choose among the vehicle models offered, they take into account their valuation of fuel economy and expectations of future fuel prices as well as the value they place on 
other vehicle attributes. Following purchase, they may also change the amount they drive and how long they keep the vehicle in response to changes in the cost of driving and in the prices of new and used vehicles.

Consumer valuation of fuel economy. Much recent work has considered whether consumers fully value the savings in fuel economy generated by CAFE (or any other action). The term "energy paradox" is often applied to the possibility that they do not fully value those savings. ${ }^{2}$ However, the concept "fully value" conflates two interrelated questions of interest for policy evaluation. One is whether consumers respond rationally to the environment they themselves face, while the other is whether that environment involves externalities that could cause even rational consumers to deviate from socially optimal behavior.

Consider first consumer rationality. While economists like to start with full rationality as a hypothesis, there is ample evidence of irrationality in consumers' behavior toward long-lived investments involving uncertain payoffs, including specifically their understanding of energy use by automobiles. ${ }^{3}$ The extent of rationality is sometimes characterized by the valuation ratio, defined as the fraction of discounted fuel cost savings that consumers consider when trading off higher vehicle prices against greater fuel efficiency. ${ }^{4}$ The variation of empirical estimates of this ratio is very wide, most falling in the range of 33-100 percent. Some authors have suggested the ratio is 100 percent, but this usually means that they cannot reject the null hypothesis of 100 percent-which is not necessarily the most theoretically likely value. ${ }^{5}$ At the other end of the

\footnotetext{
${ }^{2}$ For reviews see Helfand and Wolverton (2011), Allcott and Greenstone (2012), Gillingham and Palmer (2014), and Gerarden et al. (forthcoming).

${ }^{3}$ For example, consumers are subject to "MPG illusion" (Larrick and Soll, 2008; Allcott, 2013), by which they falsely believe that a given differential in fuel efficiency (miles per gallon or MPG) will lead to a given annul fuel saving, whatever the initial level of MPG. See Turrentine and Kurani (2007) for an overall assessment of consumer rationality in motor vehicle markets.

${ }^{4}$ This definition presumes that a known market interest rate is used for discounting. An alternative approach, more common especially in older literature, is to define the discount rate that would produce a valuation ratio of one. In this paper, I use the market interest rate for car loans, discussed later, to define valuation ratios.

${ }^{5}$ For example, Busse et al. (2013) compute the real implicit discount rates implied by prices and fuel efficiencies in both new and used car markets (their Table 9). Accounting for varying assumptions about how vehicle usage is calculated, the price elasticity of fuel usage, and the particular quartiles of fuel efficiency being compared, they compute implied discount rates ranging from -6.6 to +20.9 percent, whereas they estimate the real interest rates for car loans faced by their sample at $-0.9 \%$ to $+16.9 \%$ (p. 246). While they are thus correct to conclude that their results cannot definitively refute the hypothesis of consumer rationality, a more accurate characterization of the results is that they cannot determine whether or not there is an energy paradox. In fact, Allcott and Wozny (2014, p. 782) state that:
} 
plausible range, the default parameters for NEMS used in the Energy Information Administration's forecasts imply that the valuation ratio is only 30 percent. Our assessment is that the weight of evidence is around 80 percent, close to the value of 76 percent found in Allcott and Wozny (2014). Thus I perform simulations for valuation ratios ranging from 30 to 100 percent, with 80 percent serving as the baseline value.

Now consider social efficiency. This hinges on whether the markets for car loans and for used cars are socially efficient. Car loans, like other credit markets, are subject to problems of asymmetric information as lenders attempt to accurately gauge the riskiness of potential borrowers. To the extent that future fuel costs affect buyers' ability to repay loans, choice of fuel efficiency could be distorted; however I know of no empirical evidence relating to this.

As for used car markets, asymmetric information is well established as a source dragging down the resale value of used cars (Akerlof 1970); but whether this differentially affects cars of high and low fuel efficiency is unknown. Most evidence suggests at least that used car prices respond quickly and significantly to changes in fuel prices. ${ }^{6}$

Now consider model-building in light of possible market failures, including consumer irrationality. I take several key lessons from the literature, especially the review by Gerarden et al. (forthcoming). First, there are many ways a model can produce apparently non-optimal behavior, some by modeling behavior realistically but others by failing to capture all aspects of a decision. Second, the empirical evidence is strong that there are some behavioral non-optimalities, especially information asymmetry, salience, and principal/agent problems with commercial transactions; but their size \& even direction are quite uncertain. Third, there is great heterogeneity of consumers' responses and valuations, but it is unclear how this affects results of models that ignore it. All these possibility motivate the need to understand quantitatively how much difference various modeling choices make to predicted outcomes.

Expectations of future fuel prices. Consumers purchase vehicles based on an implicit or explicit assumption of future fuel prices. Their behavioral response to CAFE is directly related to how they form those expectations. Most research assumes either that consumers assume current

\footnotetext{
"When using assumptions that correspond most closely to ours, they [Busse et al.] find an implied discount rate for used vehicles of $13 \% "$ - a rate that is well above the average rate for car loans.

${ }^{6}$ Li et al. (2009); Busse et al. (2013); Sallee et al. (2016); Bento et al. (2017). However the opposite conclusion appears in Allcott and Wozny (2014), p. 781.
} 
fuel prices will last throughout the life of their vehicle, or that they correctly forecast the future. Recently a handful of studies have investigated this question directly, by asking consumers what prices they expect in the future. The answer, at least during the period 1992-2010, seems to be that usually they take the current price as the best predictor of future prices, but that occasionally they apply mean reversion (Anderson et al. 2013). The main example of mean reversion is that immediately after the sharp downturn in prices in late 2008, consumers expected prices to return to a level observed two years prior. A third possibility is that consumers extrapolate from values observed in the recent past to forecast fuel prices, which is what is assumed in NEMS. In this analysis, I simulate the results of all these three alternative ways that consumers could form expectations of future fuel prices.

Rebound Effect: Sensitivity of Vehicle-Miles-Traveled (VMT) to Fuel Economy. By reducing vehicle operating costs, CAFE could induce more driving and thereby offset some energy savings from improving fuel efficiency. This so-called "rebound effect" could also increase other external costs of driving, including congestion, air pollution, and traffic accidents. Because this effect is largely independent of the others, and its consequences are thoroughly explored elsewhere, I do not further consider it here.

Scrappage rates. Most analyses of CAFE ignore the used car market, but some recent studies have begun to remedy this. Li et al. (2011) and Jacobsen and van Benthem (2015) demonstrate that some motorists respond to higher new-vehicle prices resulting from tighter standards by purchasing used vehicles. This raises their prices, resulting in declining scrappage rates as people repair and continue to drive older vehicles longer than they otherwise would. Both studies also incorporate model-specific changes in scrappage rates caused by relative shifts in the prices of different vehicles.

Jacobsen and van Benthem measure an overall supply elasticity for scrappage of -0.7 , meaning that on average, an equilibrium price increase of one percent for a vehicle of any given type and age results in a 0.7 percent decrease in the fraction of such vehicles that are retired. The authors interpret this as a change in the probability that such a vehicle will face present discounted repair costs (including from accidents) greater than its price. They go on to estimate equilibrium effects on vehicle markets, including the average fuel efficiency of the total fleet of light duty vehicles, with and without a particular change in CAFE standards. 
Because NEMS lacks an explicit model of used car price determination or consumer choice between new and used cars, there is no transparent way to incorporate these findings into alternate modeling scenarios within NEMS. I therefore do not attempt to model alternate assumptions about used car markets.

Manufacturer Behavior. Many models used to analyze CAFE assume that automobile manufacturers must comply with the CAFE standards. As noted, however, the strategies they may use include adjusting vehicle prices to change the sales mix of their fleet, presumably raising the relative prices of less fuel efficient vehicles, and investing in new technologies to improve their vehicles' fuel economy. Few papers incorporate the pricing response, and fewer still do so while also allowing for technological changes. ${ }^{7}$ I do so here by modifying NEMS to allow for pricing responses.

Theory and common sense suggest that manufacturers will adjust the prices of various models to help them meet CAFE requirements in the most profitable way possible. Specifically, one expects them to raise the price of low-efficiency models (whose sales make it harder to meet the standard) and/or to lower the price of other models, so as to encourage consumers to help them meet the standard through their vehicle choices. I show in Appendix A what such profitmaximizing prices look like: basically manufacturers incorporate into their cost tradeoff a component reflecting the cost the manufacturer must incur at the margin in order to improve fuel efficiency through technology. This component can be described technically as the "shadow cost" of meeting the standard. The shadow cost is capped by the fine, if manufacturers have the option of paying a fine instead of complying and if they choose to take that option.

However, it is also important to consider non-monetary motivations for compliance. Jacobsen (2013) develops a model where manufacturers perceive a political or public-relations cost of being out of compliance. Depending on the shadow cost of meeting the standard, this may cause some firms to comply even if it would be cheaper to pay fines. Jacobsen estimates a revealed value for this political or public-relations cost. He finds it quite large for some American manufacturers in 1997-2001, a time when fuel prices were quite low: expressed as the cost per unit change in efficiency (mi/gal) per vehicle, for General Motors it is \$438 for cars and \$264 for light

\footnotetext{
${ }^{7}$ Empirical industrial organization studies, such as Berry, Levinsohn, and Pakes (1995) and Goldberg (1995), have analyzed competition in the automobile industry, but they have not accounted for both pricing and technological responses to changes in CAFE standards.
} 
trucks. I investigate the quantitative implications of such a high perceived penalties for American firms. ${ }^{8}$

In addition, I consider the possibility of policies that impose much greater penalties for non-compliance for all manufacturers. In particular, the Obama administration developed a coordinated enforcement mechanism for fuel efficiency regulations, administered by the National Highway Traffic Safety Administration (NHTSA), and for greenhouse-gas regulations, administered by the Environmental Protection Agency (EPA). Most CAFE studies have assumed that penalties for noncompliance are those set by law and administered by of NHTSA. But EPAwhose legal mandate is specifically to protect the public health - has great discretionary power and could use it to effectively increase fines. Therefore, I also consider a scenario in which penalties are five times as high as in the base scenario. This is potentially important because, as we will see, there is substantial non-compliance in the later years of the upgraded standards in some of the scenarios.

\section{The Modified NEMS Model}

\subsection{Description of NEMS 9}

The National Energy Modeling System (NEMS) is a general-equilibrium model of the US economy with emphasis on its energy sectors, developed by the Energy Information Administration (EIA). I make use only of its module covering transportation by light-duty passenger vehicles, more fully described in US EIA (2012). ${ }^{10}$ This means that I do not incorporate any general equilibrium effects via induced changes in fuel prices - an advantage in our case because such effects are uncertain and could hide the direct effects through the transportation sector.

\footnotetext{
${ }^{8}$ In contrast, Anderson and Sallee (2011, Table 8) estimate much smaller shadow costs, on the order of \$9-\$28 for all three American manufacturers, as revealed by the takeup of special provisions related to flexibly fueled vehicles. Those estimates cover years 1996-2006, but in some cases only a lower bound is estimated because, unlike Jacobsen, Anderson and Sallee assume that each firm will opt to pay the legally permitted fine if it is lower than the shadow cost.

${ }^{9}$ This description is adapted from that in Small (2012).

${ }^{10}$ I use the 2011 version of the NEMS model for the baseline forecasts, as well as the 2011 Annual Energy Outlook oil and fuel price assumptions, except as modified as explained in the text. I maintain, as appropriate, these same assumptions when I analyze alternative scenarios. NEMS has developed more recent versions of its model, but the baseline forecasts of important transportation variables do not differ much from the forecasts based on the 2011 model.
} 
In NEMS, light-duty vehicles (LDVs) are divided into two classes, cars and light trucks; each of these in turn is divided into six size classes, each intended to represent a relatively homogeneous product in terms of measurable characteristics valued by consumers. ${ }^{11}$ Each size class also encompass up to 16 fuel types, the most important of which are conventional gasoline, conventional diesel, E85 (a blend of 85 percent ethanol and 15 percent gasoline), and gasolineelectric hybrid. Finally, LDVs are produced by seven manufacturer groups, each treated by the model as a single manufacturer for determining CAFE compliance. ${ }^{12}$ Three of these groups represent foreign producers, whose reactions are fully integrated into the model.

Responses to energy markets occur in the model at several points. First, each manufacturer group chooses which technologies to adopt in a given year, taking into account consumers' valuation of attributes including fuel savings as well as CAFE regulations. ${ }^{13}$ The available technologies improve exogenously over time and their costs also exhibit the effects of pronounced industry-wide learning by doing; but no explicit process of research and development is modeled, and the technologies are basically those known today, giving the model a somewhat conservative bias in analyzing very strong policies. Manufacturers' decisions about technologies are of course shaped by their understanding of consumer response and by the regulatory regime being simulated. Those decisions produce a set of market shares for the technologies, which in turn determine the range of vehicle characteristics that are offered within each fuel type and size class.

Next, consumers as a group make several choices, modeled as aggregate demand functions. ${ }^{14}$ First, they choose the shares of cars and light trucks according to a logit-like formula

\footnotetext{
${ }^{11}$ The classes for cars are mini-compact, subcompact, compact, midsize, large, and two-seaters (sports cars); those for light trucks are small and large pickups, small and large vans, and small and large SUVs.

12 The groups are: domestic car manufacturers, imported car manufacturers, three domestic light truck manufacturers, and two imported light truck manufacturers.

13 Thus manufacturers are assumed to consider any applicable fines for CAFE violations, currently $\$ 50$ per vehicle per unit mpg deficit, as part of production costs. I have increased the fine used in the model to $\$ 100$, reflecting anticipated tougher enforcement. A more sophisticated approach is taken by Jacobsen (2013), who includes the CAFE standard as a constraint that can be violated at some fixed shadow cost (representing political considerations) plus the cost of fines; he finds that the constraint is binding on the largest U.S. manufacturers, with shadow cost for passenger cars varying from $\$ 52$ per vehicle for Ford (approximately equal to the actual fine) to \$438 for GM. This result accords with the conventional industry view that U.S. manufacturers comply with CAFE even though it would be cheaper for them to pay fines.

${ }^{14}$ An additional, simpler, module replaces consumer choices in the case of fleet vehicles, such as those of government agencies or rental companies. Fleets account for 10-20 percent of vehicle sales.
} 
that predicts the change in market share from the previous year as a function of changes in variables including income, fuel price, and new-vehicle fuel efficiency. ${ }^{15}$ Second, they choose among the six size classes available for each of the cars and light trucks according to an aggregate model that again predicts change in market share from the previous year. Third, consumers choose market shares of various fuel types through a three-level aggregate nested logit model whose variables describe vehicle price, fuel cost, range, acceleration, and other factors. EIA has calibrated the coefficients of these aggregate choice models to match known market shares in recent years, and has added some projected variation in them over time representing judgments about the likely evolution of tastes and marketing practices.

Finally, NEMS tabulates various properties of the resulting market outcomes: for example the market shares of various types of vehicles, their fuel efficiencies (including differences between testing efficiency and on-the-road efficiency), and manufacturing costs. The stock of LDVs on the road is determined by combining new-vehicle sales, as described above, with exogenous vehicle survival rates. Total VMT are modeled as a consumer choice determined by a lagged adjustment process following a log-linear regression with just two variables: income and fuel cost per mile. These VMT are apportioned exogenously by vintage, a key part of determining total energy consumption.

Despite its advantages in comprehensiveness and realism, NEMS contains several limitations for our purposes. First, choices cannot respond to various factors that might be influenced indirectly by policy, such as marketing or perceived reliability of new technologies. ${ }^{16}$ Second, manufacturers are assumed to set the price of each vehicle type equal to its average production cost, including any fines, fees, or rebates; this assumption does not allow them to use price differentials to influence sales mix as part of a strategy to meet regulations. ${ }^{17}$ Third, there is

\footnotetext{
15 This formula seems not well documented in the NEMS model descriptions, but was provided to me by OnLocation, Inc./Energy Systems Consulting, the private firm that adapted NEMS as discussed here and ran it for this study.

${ }^{16}$ I account for changing perceptions in a very limited way by adjusting a constant in the model of vehicle-type choice that expresses a preference against gasoline-electric hybrid technology, other things equal. Specifically, in analyzing the CAFE and feebate policies described below, I assume (both in the base and policy cases) that this constant diminishes gradually to zero, meaning that consumers fully accept hybrid technology by the end of the analysis period. This same change was made for an earlier version of the model used by Small $(2010,2012)$.

17 The literature contains considerable variation in its findings about how important changes in sales mix are in response to policies aimed at fuel efficiency. Whitefoot, Fowlie and Skerlos (2013), using an engineering model to
} 
no used-vehicle market, but rather scrappage of old cars is exogenous; this precludes some possibly important effects such as delayed scrappage (due to more expensive new vehicles) or differential scrappage of efficient and inefficient vehicles.

\subsection{Modifications of NEMS}

To fully assess CAFE's economic effects, I modify NEMS in several ways to better account for previously noted behavioral adjustments by consumers and automakers.

Valuation of Fuel Economy. As discussed in Section 2, I choose three scenarios for analysis: $100 \%, 80 \%$, and $30 \%$ valuations, with $80 \%$ valuation serving as the base scenario. These valuation ratios are calculated assuming the market value of $r$ is 5.16 percent — which is the projected real interest rate for car loans in NHTSA's regulatory impact analysis (NHTSA 2012, p. 991) —and that the true lifetime $T$ is 15 years, very close to the current average car lifetime. ${ }^{18}$ In the simulations, alternative valuation ratios are implemented by choosing alternative values for discount rate $r$ and time horizon $T$ as shown in Table $1 .{ }^{19}$

simulate manufacturers' design responses, find that redesign, as opposed to sales mix, accounts for nearly two-thirds of the response to a tighter CAFE standard over even a short time horizon 2011-2014.

18 The NHTSA regulatory impact analysis uses 14 years for cars and 16 for light trucks (NHTSA 2012, p. 989). Bento et al. (2016) find an average life of 15.6 years. I have calculated the valuation ratios implied by any given $r$ and $T$ as the ratio of present discounted fuel cost for the market values $(r=0.0516, T=15)$ to that for the values under consideration. The calculation uses discrete-year discounting and incorporates an expected change in fuel price of $1.35 \%$ per year, which is the average annual growth rate of the real price of motor gasoline over years 2010-2035 in the AEO 2011 reference scenario. It also uses the same age-specific declines in annual mileage with vehicle age assumed in NEMS (Lu 2006, Tables 5 and 6).

${ }^{19}$ Of course, many combinations of $r$ and $T$ could yield a given valuation ratio. For the "Market" scenario, I have chosen what I think are the true values. For the "Severe undervaluation" scenario, I use the default NEMS values of those parameters ( $r=0.15$ and $T=3$ ). For the "Moderate undervaluation" scenario ( $80 \%$ valuation), I choose to adjust $r$ rather than $T$ from its "market" value, i.e. I set $T=15$ and determine the discount rate $r$ for which the ratio of first-year fuel cost savings to present discounted value is $(0.1342 / 0.80)=0.1678$. (I call that ratio the "capital recovery factor" in Table 1 and Appendix A.) 
Table 1. Scenarios representing alternate consumer valuation of fuel cost savings

\begin{tabular}{|l|c|c|c|c|}
\hline Scenario & $\begin{array}{c}\text { Interest } \\
\text { rate }(r)\end{array}$ & $\begin{array}{c}\text { Time } \\
\text { horizon } \\
(T)\end{array}$ & $\begin{array}{c}\text { Capital } \\
\text { recovery factor } \\
(C R F)\end{array}$ & $\begin{array}{c}\text { Implied valuation } \\
\text { fraction for fuel } \\
\text { savings }^{\mathrm{a}}\end{array}$ \\
\hline Market & 0.0516 & 15 & 0.134 & 1.0 \\
\hline Partial undervaluation & 0.0936 & 15 & 0.168 & 0.8 \\
\hline Severe undervaluation & 0.1500 & 3 & 0.456 & 0.3 \\
\hline
\end{tabular}

${ }^{\mathrm{a}}$ Calculated assuming a market interest rate of 5.16 percent and true lifetime of 15 years.

In addition, I alter NEMS parameters from their default values in two other places for the "market" and "moderate undervaluation" scenarios. First is the module governing manufacturers' choice of vehicle technologies, where the interest rate and time horizon are explicit parameters and so the assumptions in Table 1 can be inserted directly into the NEMS equations. ${ }^{20}$ Second is the logit model governing consumers' choice of fuel type (e.g. conventional gasoline, hybrid, diesel, or all-electric). This model contains a utility component linear in vehicle price and expected fuel cost, whose ratio implies a particular valuation ratio; I alter the ratio of those two coefficients to be consistent with the scenario I am considering. This is described in Appendix A, Section A.2.1.

This second change requires a recalibration of two other constants in the equation governing choice of vehicle type, in order to again produce correct market shares for diesels, gaselectric hybrids, and flexible-fuel vehicles. Apparently the Energy Information Administration calibrated those constants to reproduce observed behavior in recent years (as well as to reflect its beliefs about the development of future technology), but the change in valuation ratio just

\footnotetext{
${ }^{20}$ In the simulations described in the 2011 American Energy Outlook, these parameters were specified to change unintuitively over the time of evaluation: they begin at $r=0.10$ and $T=0$, then shift to $r=0.15$ and $T=15$ for years 20172025 , then shift to $r=0.50$ and $T=1$ by the end of the projection period. I have eliminated these changing parameters and used the middle set throughout.
} 
described causes this calibration to break down. ${ }^{21}$ Those calculations are explained further in Appendix A, Section A.2.2. ${ }^{22}$

Manufacturers' pricing and technology strategies. In Appendix A.1, I show that a profitmaximizing manufacturer constrained to achieve a CAFE standard will add a price component to each vehicle which plays exactly the same role as the marginal fee or rebate in a "feebate" policy. The latter is a policy in which the manufacturer must pay the government for missing the standard or receive a rebate for exceeding the standard, the payment or rebate being proportional to how far from the standard that model car is. This differential is basically a shadow cost of fuel efficiency multiplied by the difference between the fuel efficiency of that model and the standard that applies.

Because the actual shadow cost is not known until the model is computed, actual calculation involves iterating to find the shadow cost that, when applied to all models in a given manufacturer's fleet, causes that manufacturer to meet the standard. In the calculation, any fine paid is added to this shadow cost.

I have implemented the pricing strategy in all scenarios, with the following exception. In order to explore its effect on model outcomes, I also compute a few scenarios in which such pricing is not allowed by the model. That is in fact the case in NEMS itself, so this comparison enables me to see how much it matters whether pricing responses are incorporated. I discuss those results in Section 4.2.

Non-compliance. NEMS allow firms to pay fines instead of meeting the standards if that would be less costly. As discussed earlier, the status of such fines in the future is unclear but they are likely to effectively rise. Therefore, in the base scenarios I assume the fine will be about twice the recent legal value, or $\$ 100$ per vehicle per unit deficit (in miles/gal) when a manufacturer's fleet average

\footnotetext{
${ }^{21}$ Specifically, when I alter the two coefficients just mentioned, the model no longer predicts the observed 2010 sales shares. Rather, under the market scenario, the model drastically over-predicts the market shares of diesel engines, strongly over-predicts gas-electric hybrids, and slightly over-predicts flexible-fuel vehicles. Although diesels and hybrids do not currently have large market shares, they are potentially an important part of automakers' responses to CAFE because such vehicles get high mileage; thus errors in policy evaluation can arise if I over- or under-predict their market shares.

${ }^{22}$ Starting with the default NEMS values, I first make the adjustment to reproduce the correct 2010 shares in the Market scenario. I then adjust them for the partial undervaluation scenario in proportion to the change in valuation ratio, i.e., I change them as in the market scenario but with the changes reduced by the fraction $(0.8-0.3) /(1-0.3)$.
} 
fuel efficiency falls short of the standard as applied to that manufacturer. The fine is assumed to be incorporated by the manufacturer into the price paid by the consumer.

As noted in Section 2, some researchers have found that American manufacturers perceive political or public-relations penalties for not meeting the standards. If those penalties fall below this amount, as found by Anderson and Sallee (2011), they would have a minimal effect and so the fine itself is an adequate representation. But if the implicit penalties are higher, as found by Jacobsen (2013), they would be perceived like higher fine levels. I therefore run one scenario with higher values for fines, namely $\$ 500 / \mathrm{mpg} .{ }^{23}$ I run this scenario as a variation of the "severe undervaluation" scenario, because that is the only scenario with large amounts of non-compliance.

I also modified NEMS to more accurately depict the manufacturer's cost tradeoff when considering new technologies in the presence of an option to pay fines for non-compliance. The NEMS model computes an effective shadow price for adopting more fuel efficient technologies, in terms of dollars per improvement in fuel efficiency (mi/gal). But actually the CAFE law computes the degree of non-compliance by taking a harmonic average of the efficiencies of a manufacturer's various models, i.e., it is based on the average fuel intensity (gal/mi). Thus, a manufacturer minimizing the cost of meeting the CAFE standard would presumable equalize the shadow price of reducing fuel intensity (gal/mi) across different vehicles. In the modified NEMS, therefore, I based the calculation on fuel intensity. Thus for example a technology cost or fine of $\$ 100$ per unit efficiency (mi/gal) is placed into the model as a cost or fine of $\$ 100 \cdot E^{2}$, per unit of fuel intensity (gal/mi), where $E$ is the CAFE standard expressed in $\mathrm{mi} / \mathrm{gal}$. This is because the deviation $\Delta E$ in fuel efficiency is approximately equivalent to a deviation in fuel intensity $\Delta F=-E^{2} \cdot \Delta E$. Further details are in Appendix A.3.

Consumers' expectations of fuel prices. Price expectations enter NEMS explicitly only in the vehicle manufacturers' technology choice model, where they interact with the varying assumptions about evaluation of future fuel savings. But price expectations are implicitly part of the vehicle type choice model as well, which depicts the tradeoff between vehicle price and first-year fuel cost savings. Therefore, I adapt the coefficients of both of these component models consistently.

\footnotetext{
23 This compares to an unweighted average shadow cost for General Motors, Ford, and Chrysler's car and truck fleets, measured by Jacobsen over the period 1997-2001, of \$256 per mpg.
} 
I consider three alternate assumptions about formation of price expectations. The first, is the default assumptions in NEMS: expectations in year $t$ are based on the five-year average of past prices, lagged three years (i.e., the average of prices from $t-8$ through $t-4$ ), but modified by extrapolating the change in this five-year average between $t-4$ and $t-3$ if that change was positive. The rationale is that decisions on such technological features of a vehicle must be made three years in advance. ${ }^{24}$

In the second scenario, "random walk," consumers simply use the current (real) price as the best predictor. This is in practice not much different from the consumer expectations found by Anderson et al. (2013), which differed from random walk only following the sharp downturn in 2008 - a downturn that does not occur in any of the AEO projections for future years.

In the final scenario, "rational expectations," consumers use the AEO 2011 forecast (extrapolating beyond its horizon of 2035 by using a constant growth rate of real prices based on years 2025-2035). Effectively, the "rational expectations" scenario is like "random walk" plus an expectation of a secular price rise of about 0.95 percent per year (in price of motor fuel).

Oil prices. Simulations depend strongly on the course of actual fuel prices that are modeled, given that these prices have major effects on consumers' willingness to pay for more fuel-efficient vehicles. I present two scenarios on either side of the base scenario, using the AEO 2011 "low oil price" and "high oil price" scenarios. In these scenarios, crude oil prices rise from 2010 to 2035 at average annual rates of $-3.5 \%$ and $+3.9 \%$, respectively, bracketing the rate of $1.7 \%$ in the central ("reference") scenario.

Gasoline prices vary by less than oil prices across these scenarios, ranging across annual growth rates of $-0.8 \%$ to $+2.9 \%$ (reference scenario: $1.4 \%$ ). Table 1a in the Appendix shows the projected prices of motor gasoline in these three scenarios for selected years, all in constant 2009 dollars.

In order to hold as much as possible constant across oil-price scenarios, I first ran the fully integrated NEMS system with oil prices following a given scenario, otherwise using the base assumptions. This provided an internally consistent path of prices for all the fuels used in motor

\footnotetext{
${ }^{24}$ Note this means that manufacturers are forming expectations about consumers' future expectations: specifically, manufacturers form expectations, three years in advance, concerning what fuel prices consumers will anticipate over their time horizon at time of purchase.
} 
vehicles, including electricity. I then carried out the simulations with those latter price paths held fixed - that is, as with the other simulations, macroeconomic feedbacks that might affect fuel prices endogenously are not accounted for. This makes these experiments consistent with the other experiments.

\subsection{Remaining Uncertainties}

Even with these modifications, extensive experimentation revealed some features of the model system that imply either non-optimizing behavior or implicit externalities. For example, both the original and modified versions of NEMS contain coefficients that govern consumers' willingness to consider alternative vehicle types, such as diesels or gasoline-electric hybrids, that have only a small market share currently. These coefficients were chosen to facilitate calibration of predictions with observed results in and shortly after 2010, but I know of no attempt to compare them with other evidence on how such willingness evolves over time as market shares change. Similarly, consumers' choices between cars and trucks have economic dimensions not explicitly optimized in the model, so the model system may or may not embody consumer rationality. As yet another example, the assumptions behind manufacturers' technology choices in NEMS involve strong industry-wide scale economies as well as externalities of industry-wide learning-by-doing. ${ }^{25}$

The question of whether such features accurately depict behavior in these markets, and if so whether they represent externalities, would greatly affect an overall welfare evaluation of CAFE. To the best of my knowledge, no consensus on such questions exists in the research literature. Given the importance of potential externalities to CAFE evaluation, it would be valuable to take a comprehensive look at how they are incorporated in NEMS and what is known about them.

\footnotetext{
${ }^{25}$ For example, NEMS assumes that consumers value hybrids more highly the larger the hybrid market, on the rationale that people value the service options and technical expertise of vehicle repair workers that develop only with a large market. This is reflected by including variable MMAVAIL, defined as "vehicle make and model diversity availability relative to gasoline," in the equation explain market share of gasoline-electric hybrid vehicles (EIA 2012, pp. 61-63). As another example, NEMS assumes that certain optional energy-saving technologies for conventional vehicles become cheaper as the cumulative industry-wide production of those vehicles increases (EIA 2012, pp. 19, 31). Both of these assumptions are consistent with economic theory, but it is difficult to assess whether or not the quantitative magnitudes incorporated into NEMS are realistic.
} 


\section{Results}

In order to assess the impact of CAFE, in each experiment (scenario) I run at least two cases. One is a "base case," which assumes all current policies through 2016, including CAFE increases; it then holds CAFE standards constant from 2016 on. The CAFE policies through 2016 require an approximately $26 \%$ increase in the average standard for light-duty vehicles between 2010 and 2016, from $25.3 \mathrm{mi} / \mathrm{gal}$ to 33.3 , given the assumptions about the mix of vehicle footprints made by NHTSA and EPA in their regulatory documents .

The other is a "CAFE case": it adds the recently adopted increase in standards which apply to new vehicles in years 2017-2025. This regulation is intended to raise the average standard for light-duty vehicles by another $44 \%$, to $47.9 \mathrm{mi} / \mathrm{gal}$, by year 2025 . I assume that the standards are continued as now written following the interim evaluation in 2018 which is part of the legislation. The case modeled here does not include the special credits for zero-emission vehicles, in order to make it more of a pure increase in standards unobscured by this complexity.

I simulate these two cases in a variety of scenarios, each differing in one or more of the dimensions already discussed. I begin by describing a "base scenario," which is the default assumptions from which I depart one at a time, or occasionally two at a time, in order to test the importance of those assumptions. Typically I focus on how the policy impact of the higher CAFE case (i.e. the difference from raising CAFE from 2017 onward) depends on the assumption being tested.

\subsection{Policy impacts of CAFE in base scenario}

Table 2 shows some results for the base scenario (partial valuation with price adjustments), with and without the higher CAFE standards phased in between 2017 and 2025 per current law. The first two rows show the projected gasoline prices (from AEO 2011) and the CAFE standards, ${ }^{26}$ while the remaining rows show modeled results. Note that the "base case" of this "base scenario"

\footnotetext{
${ }^{26}$ Recall that the legal requirement is not actually a specific number but rather a schedule of mandated fuel efficiencies by vehicle footprint. Thus the "standard" shown here, as well as in most descriptions of CAFE policies, results from a combination of stringency of regulations and vehicle-mix decisions by manufacturers and consumers. This is why it changes modestly after 2025 even though there is no change in the legal requirement.
} 
is essentially a forecast of what would happen if no further policy were implemented starting in 2016 except that, as already noted, it does not include special provisions favoring electric vehicles.

Table 2. Policy results: Base Scenario

Table 2. Policy Results: Base Scenario ( $80 \%$ valuation)

\begin{tabular}{|c|c|c|c|c|c|c|c|c|}
\hline & \multicolumn{3}{|c|}{ Base case } & \multicolumn{3}{|c|}{ CAFE case } & \multicolumn{2}{|c|}{ Policy impact } \\
\hline & 2015 & 2025 & 2035 & 2015 & 2025 & 2035 & 2025 & 2035 \\
\hline Inputs & & & & & & & \multicolumn{2}{|c|}{ (\% diff.) } \\
\hline Gasoline price (2010\$/gal) & 3.16 & 3.58 & 3.79 & 3.16 & 3.58 & 3.79 & $0.0 \%$ & $0.0 \%$ \\
\hline CAFE standard, avg. (mi/gal) & 31.9 & 33.7 & 34.1 & 31.9 & 48.2 & 48.8 & $42.9 \%$ & $43.2 \%$ \\
\hline \multicolumn{9}{|l|}{ Outcomes } \\
\hline Market shares & & & & & & & \multicolumn{2}{|c|}{ (\%-point diff.) } \\
\hline Conventional gasoline & $67 \%$ & $55 \%$ & $52 \%$ & $67 \%$ & $41 \%$ & $47 \%$ & $-13.8 \%$ & $-5.2 \%$ \\
\hline Diesels & $5 \%$ & $3 \%$ & $3 \%$ & $5 \%$ & $3 \%$ & $3 \%$ & $-0.3 \%$ & $0.0 \%$ \\
\hline Hybrids (excl. plug-ins) & $5 \%$ & $18 \%$ & $19 \%$ & $5 \%$ & $28 \%$ & $22 \%$ & $10.2 \%$ & $3.0 \%$ \\
\hline Plugs-ins \& dedicated elec. & $1 \%$ & $7 \%$ & $11 \%$ & $1 \%$ & $16 \%$ & $14 \%$ & $8.4 \%$ & $2.9 \%$ \\
\hline \multicolumn{2}{|c|}{ Fuel efficiency (new veh's - mi/gal): } & & & & & & \multicolumn{2}{|c|}{ (\% diff.) } \\
\hline Cars & 35.7 & 41.7 & 45.5 & 35.7 & 57.1 & 56.7 & $36.9 \%$ & $24.7 \%$ \\
\hline Trucks & 27.3 & 35.6 & 39.6 & 27.3 & 41.3 & 41.4 & $16.0 \%$ & $4.5 \%$ \\
\hline All LDVs & 31.2 & 38.9 & 43.0 & 31.2 & 48.8 & 49.3 & $25.4 \%$ & $14.6 \%$ \\
\hline \multicolumn{9}{|c|}{ Fuel efficiency - veh stock (mi/gal): } \\
\hline All LDVs & 22.2 & 26.8 & 31.5 & 22.2 & 28.7 & 36.2 & $7.1 \%$ & $14.9 \%$ \\
\hline VMT (billions) & 2,966 & 3,518 & 4,145 & 2,966 & 3,542 & 4,206 & $0.7 \%$ & $1.5 \%$ \\
\hline Fuel use (billions gal) & 134 & 131 & 132 & 134 & 123 & 116 & $-6.0 \%$ & $-11.7 \%$ \\
\hline
\end{tabular}

The base (no-policy) case suggests that when consumers value fuel savings at 80 percent of their objective value, manufacturers go part way toward achieving the higher CAFE standards even when they are not imposed. I use year 2025 as a convenient milepost, since that is when the new standards, if imposed, would fully take effect. That standard, calculated at the expected mix of vehicle sizes endogenously chosen in 2025 , is $48.2 \mathrm{mi} / \mathrm{gal}$, resulting in a 56 percent increase in average new-vehicle fuel efficiency over the previous ten years; but even when the standard is not imposed, fuel efficiency rises by 24 percent. ${ }^{27}$ As a result, the policy impact of the higher standard

\footnotetext{
${ }^{27}$ Even in the base case, CAFE standards rise slightly through 2016 due to earlier regulations. Furthermore, slight changes in the anticipated mix of footprint sizes cause the effective standard as calculated here to rise to 33.7 by 2025 in the base case, as shown in Table 2.
} 
on fuel efficiency (a gain of about 25 percent) is much less than the change in the standard itself (which increases by 44 percent). The policy impact in 2035 is even smaller, as manufacturers would continue to increase efficiency even in the base scenario; this is due to a combination of continuing fuel-price increases, declines in technology costs over time, and the model's assumption about technological inertia - namely, that once a new technology is adopted, it is not abandoned.

This finding, that fuel economy is moderately high even without an increase in CAFE, is driven by the robust consumer demand for fuel-efficient cars in this scenario, coupled with the gradual increase in gasoline price. As we shall see, it is strongly dependent on the assumed valuation of cost savings by consumers.

As part of the market adjustment with or without higher CAFE standards, there are significant shifts in the market shares of unconventional engines. Conventional diesels remain a small share, but hybrids (both gasoline-electric and diesel-electric) rise significantly by 2025 , to a $18 \%$ share even without the CAFE policy and $28 \%$ with it. Interestingly, with the policy in place (but no increase in stringency after 2025), the market share of hybrids falls back by several percentage points after 2025, as other technologies come on line to achieve the fuel standards without requiring the more expensive hybrid technology. ${ }^{28}$ Thus, it appears that hybrid technologies are key to achieving those last increments of fuel efficiency demanded by the 2025 standards.

Vehicles using external electric power — plug-in hybrids and dedicated electrics — also gain market share, to about $7 \%$ in 2025 without the higher standards and $16 \%$ with them. (They decline in share after 2035 in the CAFE case, for the same reason as hybrids.) In actuality, vehicles with batteries will probably grow in market share more than projected here due to recent faster-thanexpected advances in battery technology. This is especially true for all-electric vehicles if current provisions giving double credits for zero-emission vehicles (such credits being included in neither the base case nor CAFE case as modeled here) are retained.

The vehicle fleet, of course, does not change nearly as quickly as the cohort of new vehicles. As a result, fleet fuel efficiency rises less dramatically with standards, by $7.1 \%$ in 2025

\footnotetext{
${ }^{28}$ This can occur in the model partly because the market share of hybrids is chosen by consumers through an explicit choice model, whereas the adoption of technologies on conventional vehicles is chosen by manufacturers based on assumed paths of technology costs.
} 
and $14.9 \%$ in 2035 . Actual fuel use falls by even less, due to the rebound effect causing VMT to be somewhat higher in the policy case.

\subsection{Effects of price adjustments}

Table 3 shows selected results with and without the price adjustments that I incorporate into most of the scenarios. Results are shown for year 2025. The CAFE standards are footprintbased - that is, they are more lenient the larger the surface area covered by the wheels of the vehicle.

Table 3. Effects of price adjustments, 2025

\begin{tabular}{|c|c|c|c|c|c|c|}
\hline & \multicolumn{3}{|c|}{ Base $(80 \%)$} & \multicolumn{3}{|c|}{ Base $(80 \%)$ w/o price adj } \\
\hline & Base & CAFE & $\begin{array}{r}\text { CAFE } \\
\text { impact } \\
\end{array}$ & Base & CAFE & $\begin{array}{r}\text { CAFE } \\
\text { impact } \\
\end{array}$ \\
\hline $\begin{array}{l}\text { Average new-vehicle fuel economy } \\
\text { (mi/gal): }\end{array}$ & & & (\% diff.) & & & (\% diff.) \\
\hline All light-duty vehicles & 38.9 & 48.8 & $25.4 \%$ & 39.2 & 46.8 & $19.4 \%$ \\
\hline Conventional gasoline car & 37.0 & 43.9 & $18.7 \%$ & 37.3 & 47.9 & $28.3 \%$ \\
\hline Conventional gasoline truck & 31.2 & 34.9 & $11.7 \%$ & 31.4 & 36.5 & $16.4 \%$ \\
\hline Sales share by vehicle type: & & & (diff in $\%$ pts) & & & (diff in $\%$ pts \\
\hline Conventional gasoline & $55.3 \%$ & $41.5 \%$ & $-13.8 \%$ & $55.1 \%$ & $56.3 \%$ & $1.2 \%$ \\
\hline Diesel & $3.0 \%$ & $2.6 \%$ & $-0.3 \%$ & $2.9 \%$ & $2.6 \%$ & $-0.4 \%$ \\
\hline Hybrids (excl. plug-ins) & $17.5 \%$ & $27.7 \%$ & $10.2 \%$ & $17.5 \%$ & $16.5 \%$ & $-1.0 \%$ \\
\hline Plugin hybrids + dedicated electric & $7.3 \%$ & $15.7 \%$ & $8.4 \%$ & $7.3 \%$ & $7.0 \%$ & $-0.3 \%$ \\
\hline \multicolumn{7}{|l|}{ Sales share by technology used: } \\
\hline Micro hybrid (engine off at idle) & $19.1 \%$ & $48.9 \%$ & $29.7 \%$ & $21.1 \%$ & $61.8 \%$ & $40.7 \%$ \\
\hline Material subst'n (most advanced) & $1.4 \%$ & $31.6 \%$ & $30.3 \%$ & $1.4 \%$ & $56.9 \%$ & $55.5 \%$ \\
\hline
\end{tabular}

There are several striking differences in how markets are predicted to respond to stricter CAFE standards if manufacturers' pricing responses are not accounted for. First, the average fuel efficiency of new vehicles with the higher CAFE standard in place would be about four percent lower without pricing: the 2025 standard of $48.2 \mathrm{mi} /$ gal would not be met, whereas it is met and even slightly exceeded with pricing responses allowed.

Second, without pricing, more effort would be put into technologies on conventional gasoline cars, and less into increasing the market share of unconventional engines. Indeed, as seen 
in the second and third rows of numbers, with higher CAFE regulations the efficiency of conventional gasoline vehicles rises by several percentage points more when pricing flexibility is absent. But this is more than compensated by the much smaller penetration of hybrids and other unconventional vehicles when pricing response is unavailable.

The manner in which conventional gasoline engines are improved is exemplified by two technologies, shown in the last two rows of the table: automatic powering off (so-called "microhybrid" technology), and advanced material substitution to reduce vehicle weight. ${ }^{29}$ Essentially, manufacturers unable to influence consumer purchases by pricing must instead invest in expensive technologies for each given type of vehicle in order to raise average fuel efficiency.

Just how expensive this is can be seen in Table 4. In the non-price-responsive scenario, the manufacturer's costs of making various types of new vehicles rise by significantly more than in the price-adjustment scenario. Table 4 also shows some examples of the price adjustments themselves, when they are allowed by the model: they range between roughly $\$ 750$ and $\$ 1750$ per vehicle in magnitude, which is about $3 \%$ to $6 \%$ of the manufacturer's cost. ${ }^{30}$

\footnotetext{
${ }^{29}$ The Energy Information Administration defines micro hybrid vehicles as "vehicles with gasoline engines, larger batteries, and electrically powered auxiliary systems that allow the engine to be turned off when the vehicle is coasting or idling and then quickly restarted. Regenerative braking recharges the batteries..." (EIA 2012, p. 30). However I use the slightly narrower definition used in the EIA's detailed charts, namely "Engine off at idle".

${ }^{30}$ This cost includes return to capital and a normal profit.
} 
Table 4. Effects of price adjustments on selected vehicle costs, 2025

\begin{tabular}{|c|c|c|c|c|c|c|}
\hline & \multicolumn{3}{|c|}{ With price adjustments } & \multicolumn{3}{|c|}{ Without price adjustments } \\
\hline & Base & CAFE & $\begin{array}{l}\text { CAFE } \\
\text { impact }\end{array}$ & Base & CAFE & $\begin{array}{l}\text { CAFE } \\
\text { impact }\end{array}$ \\
\hline Vehicle cost (2010\$): & & & (\% diff.) & & & (\% diff.) \\
\hline Midsize car (conv gasoline) & 28,235 & 29,874 & $5.8 \%$ & 28,349 & 30,665 & $8.2 \%$ \\
\hline Small SUV (conv gasoline) & 25,941 & 27,096 & $4.5 \%$ & 25,988 & 27,573 & $6.1 \%$ \\
\hline Midsize car (gas-elec hybrid)) & 34,255 & 35,013 & $2.2 \%$ & 34,302 & 35,967 & $4.9 \%$ \\
\hline Small SUV (gas-elec hybrid)) & 31,449 & 32,014 & $1.8 \%$ & 31,466 & 32,362 & $2.8 \%$ \\
\hline Vehicle price markup (2010\$): & & & $\begin{array}{c}\text { (\% of cost in } \\
\text { base case) }\end{array}$ & & & $\begin{array}{c}(\% \text { of cost in } \\
\text { base case) }\end{array}$ \\
\hline Midsize car (conv gasoline) & 0 & 1,742 & $6.2 \%$ & 0 & 0 & $\mathbf{0 . 0 \%}$ \\
\hline Small SUV (conv gasoline) & 0 & 752 & $2.9 \%$ & 0 & 0 & $0.0 \%$ \\
\hline Midsize car (gas-elec hybrid)) & 0 & -951 & $-2.8 \%$ & 0 & 0 & $0.0 \%$ \\
\hline Small SUV (gas-elec hybrid)) & 0 & $-1,089$ & $-3.5 \%$ & 0 & 0 & $0.0 \%$ \\
\hline
\end{tabular}

In the "severe undervalue" scenario (30\% valuation), presented in the next subsection, the importance of price adjustment is even greater. Results like those in Tables 3 and 4 are shown in Appendix B, as Tables 3a and 4a, for 30\% valuation. (They also differ by assuming a higher fine, which is needed to achieve results approaching the CAFE standard with such low valuation by consumers.) In those scenarios, the CAFE policy would again cause micro-hybrids to gain well over half the conventional-car market without price adjustments, but only $16 \%$ with price adjustments. With pricing response, price markups and markdowns are much larger with severe undervaluation of fuel efficiency, as manufacturers struggle to shift consumers from conventional to unconventional engines.

\subsection{Effects of consumer valuation of fuel price savings}

Tables 5 and 6 shows results comparable to Tables 3 and 4, this time comparing the base scenario ( $80 \%$ valuation) to the "severe undervalue" scenario (30\% valuation). We see that with severe undervaluation, manufacturers and consumers do not respond strongly to rising gasoline prices in the absence of stricter regulation, causing the policy impacts of CAFE - as measured by the differences in fuel economy, sales shares, and technology application - to be much greater. When CAFE is applied in this scenario, manufacturers shift to hybrids even more strongly, but make little use of expensive technologies for conventional vehicles, such as micro-hybrids and 
advanced materials (Table 5). In addition, with severe undervaluation manufacturers rely more on price incentives, for example applying a price markup to a conventional midsize car equal to $15 \%$ of its base cost, more than twice the markup applied in the base scenario (Table 6).

Table 5. Effects of valuation, 2025

\begin{tabular}{|c|c|c|c|c|c|c|}
\hline & \multicolumn{3}{|c|}{ Partial valuation $(80 \%)$} & \multicolumn{3}{|c|}{ Severe undervalue $(30 \%)$} \\
\hline & Base & CAFE & $\begin{array}{l}\text { CAFE } \\
\text { impact }\end{array}$ & Base & CAFE & $\begin{array}{c}\text { CAFE } \\
\text { impact } \\
\end{array}$ \\
\hline $\begin{array}{l}\text { Average new-vehicle fuel economy } \\
\text { (mi/gal): }\end{array}$ & & & (\% diff.) & & & (\% diff.) \\
\hline All light-duty vehicles & 38.9 & 48.8 & $25.4 \%$ & 34.9 & 48.7 & $39.6 \%$ \\
\hline Conventional gasoline car & 37.0 & 43.9 & $18.7 \%$ & 35.5 & 39.1 & $10.3 \%$ \\
\hline Conventional gasoline truck & 31.2 & 34.9 & $11.7 \%$ & 27.4 & 32.0 & $16.8 \%$ \\
\hline Sales share by vehicle type: & & \multicolumn{2}{|c|}{ (diff in \% pts) } & & & (diff in \% pts) \\
\hline Conventional gasoline & $55.3 \%$ & $41.5 \%$ & $-13.8 \%$ & $60.7 \%$ & $34.0 \%$ & $-26.8 \%$ \\
\hline Diesel & $3.0 \%$ & $2.6 \%$ & $-0.3 \%$ & $4.2 \%$ & $4.8 \%$ & $0.6 \%$ \\
\hline Hybrids (excl. plug-ins) & $17.5 \%$ & $27.7 \%$ & $10.2 \%$ & $11.9 \%$ & $31.2 \%$ & $19.3 \%$ \\
\hline Plugin hybrids + dedicated electric & $7.3 \%$ & $15.7 \%$ & $8.4 \%$ & $5.4 \%$ & $21.4 \%$ & $16.0 \%$ \\
\hline \multicolumn{7}{|l|}{ Sales share by technology used: } \\
\hline Micro hybrid (engine off at idle) & $19.1 \%$ & $48.9 \%$ & $29.7 \%$ & $5.9 \%$ & $16.8 \%$ & $10.9 \%$ \\
\hline Material subst'n (most advanced) & $1.4 \%$ & $31.6 \%$ & $30.3 \%$ & $0.5 \%$ & $6.3 \%$ & $5.7 \%$ \\
\hline
\end{tabular}


Table 6. Effects of valuation on selected vehicle costs, 2025

\begin{tabular}{|c|c|c|c|c|c|c|}
\hline & \multicolumn{3}{|c|}{ Partial valuation $(80 \%)$} & \multicolumn{3}{|c|}{ Severe undervalue $(30 \%)$} \\
\hline & Base & CAFE & $\begin{array}{c}\text { CAFE } \\
\text { impact } \\
\end{array}$ & Base & CAFE & $\begin{array}{c}\text { CAFE } \\
\text { impact } \\
\end{array}$ \\
\hline Vehicle cost (2010\$): & & & (\% diff.) & & & (\% diff.) \\
\hline Midsize car (conv gasoline) & 28,235 & 29,889 & $\mathbf{5 . 9 \%}$ & 27,880 & 28,562 & $2.4 \%$ \\
\hline Small SUV (conv gasoline) & 25,941 & 27,103 & $4.5 \%$ & 25,076 & 26,107 & $4.1 \%$ \\
\hline Midsize car (gas-elec hybrid)) & 34,255 & 35,005 & $2.2 \%$ & 34,148 & 34,426 & $0.8 \%$ \\
\hline Small SUV (gas-elec hybrid)) & 31,449 & 32,005 & $1.8 \%$ & 31,490 & 31,885 & $1.3 \%$ \\
\hline Vehicle price markup (2010\$): & & & $\begin{array}{c}\text { (\% of cost in } \\
\text { base case) }\end{array}$ & & & $\begin{array}{c}\text { \% of cost in } \\
\text { base case) }\end{array}$ \\
\hline Midsize car (conv gasoline) & 0 & 1,726 & $6.1 \%$ & 0 & 4,199 & $15.1 \%$ \\
\hline Small SUV (conv gasoline) & 0 & 746 & $2.9 \%$ & 0 & 2,696 & $10.7 \%$ \\
\hline Midsize car (gas-elec hybrid)) & 0 & -943 & $-2.8 \%$ & 0 & -762 & $-2.2 \%$ \\
\hline Small SUV (gas-elec hybrid)) & 0 & $-1,080$ & $-3.4 \%$ & 0 & $-2,007$ & $-6.4 \%$ \\
\hline
\end{tabular}

As expected, the "full valuation" scenario differs in the opposite direction; I show it in Appendix B, Tables 5a and 6a. In that scenario, average fuel efficiency in 2025 under the base case (no increase in CAFE) is $40.8 \mathrm{mi} / \mathrm{gal}$, a little higher than under "Partial undervaluation;" whereas hybrid penetration is $20.6 \%$, also somewhat higher. Because efficiency is somewhat higher even without the boost in CAFE standards, that boost has less impact in this scenario: the policy impact on efficiency of new light-duty vehicles in 2025 is $19.4 \%$, aided by an 8.2 percentage-point increase in hybrid share.

I also explored two intermediate scenarios, with $60 \%$ and $45 \%$ valuation, shown in the same tables in Appendix B. As expected, results mostly vary smoothly with the degree of valuation. ${ }^{31}$

\subsection{Effects of magnitudes of fines for non-compliance}

\footnotetext{
${ }^{31}$ There is an apparent small lack of monotonicity in CAFE impacts on vehicle prices. This is probably due to minor quirks in the model involving when particular discrete technologies are introduced. The vehicle prices themselves are monotonic; but the prices in the reference case vary with valuation at slightly different rates from those in the CAFE case, so their differences are not monotonic.
} 
In this subsection I report the result of raising the fine by a factor of five, to $\$ 500$ (in 1990 \$) per vehicle per unit deviation from the standard as stated in miles per gallon. I test this in combination within the "severe undervaluation" scenario, because that is the only scenario with large amounts of non-compliance.

I do not show numerical results for the base scenario (with price adjustments accounted for), because there is almost full compliance with CAFE even with the lower fine. As a result, raising the fine makes practically no difference to the outcome except for the amounts paid in fines in the high CAFE cases - which is still not very large. ${ }^{32}$ These fines are paid entirely by the manufacturing group representing sports cars, ${ }^{33}$ whose market share is small. Note that the model assumes that manufacturers pass these fines on to their customers.

The scenario with high fines calls further attention to the importance of accounting for price adjustments in order to model responses accurately. When price adjustments are not accounted for, high fines are predicted to have discernable impacts on achieved fuel efficiency, on manufacturing costs, and on the sales shares of unconventional cars. Tables 7 and 8 compare the predicted impacts of low and high fines if price adjustments are ignored. They show that without price adjustments, the year-2025 impacts of high CAFE would be predicted to be about 3 percentage points greater on achieved fuel economy with high compared to low fines (although still not quite meeting the standards); 6 percentage points greater in the use of micro hybrids; and 10 percentage points greater in use of the most advanced materials. The costs of individual vehicle types and classes would be predicted to rise about two percentage points more with high fines than with low fines (Table 8). Fines paid would rise to more than $\$ 1,900$ per vehicle on average for cars (much less for light trucks). More detailed figures, not shown in the tables, reveal that the fines are also more widespread in this scenario, ranging across manufacturing groups from approximately $\$ 1,300$ to $\$ 9,400$ per vehicle for cars, and from zero to $\$ 250$ per vehicle for light trucks.

\footnotetext{
32 The fine paid is an average of $\$ 81$ per vehicle in year 2025 , compared to $\$ 16$ in the low-fine scenario.

33 These fines amount to $\$ 14,200$ per vehicle in the high-fine scenario.
} 
Table 7. Effects of fines, 2025

(Severe Undervalue scenarios, without price adjustments)

\begin{tabular}{|c|c|c|c|c|c|c|}
\hline \multirow[b]{3}{*}{$\begin{array}{l}\text { Average new-vehicle fuel economy } \\
\text { (mi/gal): }\end{array}$} & \multicolumn{3}{|c|}{ Standard fines } & \multicolumn{3}{|c|}{ High fines } \\
\hline & Base & CAFE & $\begin{array}{l}\text { CAFE } \\
\text { impact }\end{array}$ & Base & CAFE & $\begin{array}{l}\text { CAFE } \\
\text { impact }\end{array}$ \\
\hline & & & (\% diff.) & & & (\% diff.) \\
\hline All light-duty vehicles & 35.8 & 46.4 & $29.5 \%$ & 35.8 & 47.4 & $32.4 \%$ \\
\hline Conventional gasoline car & 36.3 & 47.8 & $31.8 \%$ & 36.3 & 49.0 & $35.2 \%$ \\
\hline Conventional gasoline truck & 28.0 & 36.8 & $31.7 \%$ & 28.0 & 37.6 & $34.5 \%$ \\
\hline Sales share by vehicle type: & & & (\%-pt diff) & & & (\%-pt diff) \\
\hline Conventional gasoline & $60.3 \%$ & $59.1 \%$ & $-1.2 \%$ & $60.3 \%$ & $59.6 \%$ & $-0.6 \%$ \\
\hline Diesel & $3.6 \%$ & $3.8 \%$ & $0.2 \%$ & $3.6 \%$ & $3.8 \%$ & $0.3 \%$ \\
\hline Hybrids (excl. plug-ins) & $12.4 \%$ & $13.5 \%$ & $1.1 \%$ & $12.4 \%$ & $13.2 \%$ & $0.7 \%$ \\
\hline Plugin hybrids + dedicated electric & $5.7 \%$ & $6.3 \%$ & $0.6 \%$ & $5.7 \%$ & $5.9 \%$ & $0.2 \%$ \\
\hline Sales share by technology used: & & & & & & \\
\hline Micro hybrid (engine off at idle) & $9.2 \%$ & $55.9 \%$ & $46.7 \%$ & $9.2 \%$ & $61.4 \%$ & $52.3 \%$ \\
\hline Material subst'n (most advanced) & $0.4 \%$ & $53.6 \%$ & $53.2 \%$ & $0.4 \%$ & $64.0 \%$ & $63.6 \%$ \\
\hline
\end{tabular}

Table 8. Effects of fines on selected vehicle costs, 2025 (Severe Undervalue scenarios, without price adjustments)

\begin{tabular}{|c|c|c|c|c|c|c|}
\hline & \multicolumn{3}{|c|}{ Standard fines } & \multicolumn{3}{|c|}{ High fines } \\
\hline & Base & CAFE & $\begin{array}{r}\text { CAFE } \\
\text { impact } \\
\end{array}$ & Base & CAFE & $\begin{array}{l}\text { CAFE } \\
\text { impact } \\
\end{array}$ \\
\hline Vehicle cost (2010\$): & & & (\% diff.) & & & (\% diff.) \\
\hline Midsize car (conv gasoline) & 28,097 & 30,267 & $7.7 \%$ & 28,097 & 30,803 & $9.6 \%$ \\
\hline Small SUV (conv gasoline) & 25,207 & 27,130 & $7.6 \%$ & 25,207 & 27,708 & $9.9 \%$ \\
\hline Midsize car (gas-elec hybrid)) & 34,246 & 35,414 & $3.4 \%$ & 34,246 & 36,194 & $5.7 \%$ \\
\hline Small SUV (gas-elec hybrid)) & 31,536 & 32,128 & $1.9 \%$ & 31,536 & 32,803 & $4.0 \%$ \\
\hline $\begin{array}{l}\text { Fines paid in lieu of compliance } \\
\text { (\$/vehicle): }\end{array}$ & & & $\begin{array}{l}\text { (\% of base- } \\
\text { case price) }\end{array}$ & & & $\begin{array}{l}\text { (\% of base- } \\
\text { case price) }\end{array}$ \\
\hline Cars & 4 & 587 & $2.1 \%$ & 4 & 1,918 & $6.9 \%$ \\
\hline Trucks & 0 & 86 & $0.3 \%$ & 0 & 55 & $0.2 \%$ \\
\hline
\end{tabular}

\subsection{Effects of fuel price expectations}

Alternative fuel price expectations turn out to have little effect on the simulations. Some results are shown in Table $3 \mathrm{~b}$ in Appendix B, comparing the NEMS default expectations with random walk expectations (i.e., expected price is the same as the current price except for a constant trend growth). The CAFE impact on new-vehicle fuel efficiency is just 1.0 percentage point greater with random walk. This is mainly because the current price is almost always equal to or 
slightly less than NEMS-default expectations, leading consumers to choose slightly less fuel efficiency in the base case. Rational expectations are very similar to random-walk expectations.

These results are due mainly to the very slow growth in fuel prices in the AEO projections, and also to their lack of volatility. For this reason, I thought there might be a greater difference if I used the AEO "High oil price" scenario as a starting point, but that proved not to be the case. Even that scenario has very modest growth in oil prices (see next subsection) over the periods of interest here, namely after 2017; most of the difference occurs in the years 2010-2015. That comparison is shown in the appendix as Table 3c. (In this case, I show rational expectations; once again, random walk is very similar.)

If the AEO projections included randomly generated volatility, comparable to past volatility, there would be more differences because the NEMS default expectations would reflect the occasional large upward trend that consumers would project from a particular one-year increase in fuel price. This would cause the NEMS default to produce higher fuel economy without CAFE, hence a smaller impact of CAFE. But such results would be suspect on several grounds. First, there is only scant evidence that consumers have such one-sided expectations, coming from a single episode of a price drop in 2008 which, according to surveys, consumers expected (correctly) to be reversed (Anderson et al. 2013). Second, the trend extrapolation assumed in NEMS on the part of consumers is very specific and arbitrary, whereas the evidence just cited suggests that consumers are more nuanced in their projections. Third, any quantitative forecasts of future volatility in fuel prices would be highly uncertain themselves, compounding the uncertainty in forecasts of price levels.

Finally, it seems likely that consumers react to volatility itself, as opposed to simply using it to change their forecasts of future prices. However, it is not clear in which direction price volatility would tilt their decisions. If they view a new car as a significant investment, they may defer purchase, hoping that some of the uncertainty in future prices is resolved; this could be represented in NEMS as a volatility-dependent lengthening of the average age of vehicle scrappage. On the other hand, risk aversion could cause consumers to invest in extra fuel efficiency as a hedge against the risk of finding themselves trapped with a car too expensive to operate. To model this properly would require new research into consumer reactions.

I also explored whether the extent of under-valuation of fuel efficiency affects the impacts of alternative price expectations, but found that any such effects are small. The relevant impacts 
for the case of severe undervaluation are shown in Appendix B as Table 3d. Roughly speaking, changing fuel price expectations has similar effects to making small changes in valuation: they affect CAFE impact by changing the base case.

\subsection{Effects of fuel prices}

One can expect the course of fuel prices to have large effects on the base case (without high CAFE), especially in those scenarios when consumers value a high fraction of the cost savings from fuel efficiency. The higher the fuel price, the more consumers will adopt high efficiency voluntarily and therefore the impact of standards will be smaller.

Table 9 shows that this is indeed the case. I use the base assumptions (which include price expectations informed by recent price movements) in all respects except for replacing EIA's standard scenario with its "low oil price" or "high oil price" scenario. The low and high oil price projections result in manufacturers voluntarily achieving 34.8 and $43.1 \mathrm{mi} / \mathrm{gal}$, respectively (vs. $38.9 \mathrm{mi} / \mathrm{gal}$ under the Reference Case forecast), even without the imposition of new CAFE standards. The latter figure is 87 percent of the level (48.8 mi/gal) achieved in the same scenario with the higher CAFE in place. 
Table 9. Effects of oil prices, 2025

\begin{tabular}{|c|c|c|c|c|c|c|}
\hline & \multicolumn{3}{|c|}{ Low Oil Price } & \multicolumn{3}{|c|}{ High Oil Price } \\
\hline & Base & CAFE & $\begin{array}{c}\text { CAFE } \\
\text { impact }\end{array}$ & Base & CAFE & $\begin{array}{c}\text { CAFE } \\
\text { impact }\end{array}$ \\
\hline $\begin{array}{l}\text { Average new-vehicle fuel economy } \\
\text { (mi/gal): }\end{array}$ & & & (\% diff.) & & & (\% diff.) \\
\hline All light-duty vehicles & 34.8 & 47.3 & $35.9 \%$ & 43.1 & 49.6 & $15.1 \%$ \\
\hline Conventional gasoline car & 36.1 & 41.7 & $15.5 \%$ & 39.7 & 45.1 & $13.6 \%$ \\
\hline Conventional gasoline truck & 28.9 & 33.7 & $16.3 \%$ & 34.7 & 36.9 & $6.4 \%$ \\
\hline Sales share by vehicle type: & & & (diff in \% pts) & & & (diff in $\%$ pts) \\
\hline Conventional gasoline & $61.1 \%$ & $37.2 \%$ & $-23.9 \%$ & $40.9 \%$ & $37.6 \%$ & $-3.4 \%$ \\
\hline Diesel & $2.0 \%$ & $1.9 \%$ & $-0.1 \%$ & $3.8 \%$ & $3.7 \%$ & $-0.1 \%$ \\
\hline Hybrids (excl. plug-ins) & $11.4 \%$ & $31.6 \%$ & $20.1 \%$ & $20.6 \%$ & $24.7 \%$ & $4.1 \%$ \\
\hline Plugin hybrids + dedicated electric & $4.3 \%$ & $17.2 \%$ & $12.9 \%$ & $9.8 \%$ & $14.5 \%$ & $4.7 \%$ \\
\hline Sales share by technology used: & & & & & & \\
\hline Micro hybrid (engine off at idle) & $15.7 \%$ & $37.4 \%$ & $21.7 \%$ & $36.9 \%$ & $57.3 \%$ & $20.5 \%$ \\
\hline Material subst'n (most advanced) & $0.5 \%$ & $17.5 \%$ & $17.0 \%$ & $5.2 \%$ & $35.5 \%$ & $30.4 \%$ \\
\hline
\end{tabular}

With CAFE in place, manufacturers over-comply on average when oil prices are high, leading to a 5 percent higher average fuel efficiency than with low oil prices. It is interesting to see how this is accomplished. With high prices, conventional gasoline vehicles, mainly cars, have their efficiencies boosted even further, through technologies exemplified by the projected high penetration of micro hybrids and a big increase in the use of advanced materials. Comparing the two oil-price scenarios, advanced material use spans the range from just 0.5 percent in the base case with low oil prices to over 35 percent in the CAFE scenario with high oil prices. Use of gaselectric hybrids also increases when CAFE is adopted, but in the high oil price scenario this effect is small: apparently, given the technology assumptions modeled here, when consumers are willing to spend money on fuel efficiency, manufacturers prefer to put a lot of technology into conventional gasoline cars rather than market hybrids and electric cars extensively.

This strategy for meeting CAFE can be seen in Table 10, which shows manufacturing costs (upper panel) and price markups adopted as incentives (lower panel), for selected vehicles. The price markups are quite large in the low oil price scenario, which is a major reason for the increase 
in hybrid and electric market shares. In the high oil price scenario, markups are more modest, indicating that the constraint imposed by CAFE is less tightly binding. ${ }^{34}$

Table 10. Effects of oil prices on selected vehicle costs, 2025

\begin{tabular}{|c|c|c|c|c|c|c|}
\hline & \multicolumn{3}{|c|}{ Low Oil Price } & \multicolumn{3}{|c|}{ High Oil Price } \\
\hline & Base & CAFE & $\begin{array}{l}\text { CAFE } \\
\text { impact }\end{array}$ & Base & CAFE & $\begin{array}{c}\text { CAFE } \\
\text { impact }\end{array}$ \\
\hline Vehicle manuf. cost (2010\$): & & & (\% diff.) & & & (\% diff.) \\
\hline Midsize car (conv gasoline) & 28,174 & 29,329 & $4.1 \%$ & 28,899 & 30,154 & $4.3 \%$ \\
\hline Small SUV (conv gasoline) & 25,485 & 26,682 & $4.7 \%$ & 26,796 & 27,393 & $2.2 \%$ \\
\hline Midsize car (gas-elec hybrid)) & 34,231 & 34,641 & $1.2 \%$ & 34,457 & 35,323 & $2.5 \%$ \\
\hline Small SUV (gas-elec hybrid)) & 31,282 & 31,782 & $1.6 \%$ & 31,812 & 32,201 & $1.2 \%$ \\
\hline Vehicle price markup (2010\$): & & & $\begin{array}{c}(\% \text { of cost in } \\
\text { base case) }\end{array}$ & & & $\begin{array}{c}(\% \text { of cost in } \\
\text { base case) }\end{array}$ \\
\hline Midsize car (conv gasoline) & 0 & 3,658 & $13.0 \%$ & 0 & 892 & $3.1 \%$ \\
\hline Small SUV (conv gasoline) & 0 & 2,037 & $8.0 \%$ & 0 & 118 & $0.4 \%$ \\
\hline Midsize car (gas-elec hybrid)) & 0 & $-1,195$ & $-3.5 \%$ & 0 & -609 & $-1.8 \%$ \\
\hline Small SUV (gas-elec hybrid)) & 0 & $-2,023$ & $-6.5 \%$ & 0 & -224 & $-0.7 \%$ \\
\hline
\end{tabular}

\subsection{Non-footprint-based standards}

As noted earlier, the current form of CAFE standards makes them more lenient for larger vehicles, as measured by the surface area covered by its wheels (its "footprint"). This feature is intended to prevent the standards from creating incentives to make vehicles smaller in their footprint. This raises the question: would the regulations be more effective, or less costly, if they were not based on the vehicle's footprint?

I consider a scenario in which the connection between the standard and the vehicle size is partially relaxed, by means of what I call a dual standard: one standard for all cars, another for all light trucks. This is in fact the approach that prevailed for most of the U.S. CAFE regulations'

\footnotetext{
${ }^{34}$ The differences are not due to different degrees of compliance: in both scenarios all manufacturers comply except the group that makes sports cars; the latter does not even fully comply in the base case, indicating their cars are not quite meeting the 2016 standard even by 2025 .
} 
history, being supplanted by a gradual transition to footprint-based standards starting in 2008. The dual standard still forgoes one incentive, which may be important: to shift from light trucks to cars. However, for technical reasons it would be difficult to modify NEMS to simulate such a uniform standard.

Tables 11 and 12 show the results, using the base scenario for all other aspects. Table 11 shows that the type of standards makes only a small improvement in achieved fuel efficiency. The dual standard results in slightly more unconventional vehicles, and little change in use of advanced technologies for conventional vehicles. Table 12 shows that there is little effect on the vehicle size mix, with the dual standard inducing a small increase in the market share of compact cars but also (inexplicably) in that of large pickup trucks. All these differences are small enough to be within the probably margins of modeling error.

Table 11. Effects of dual CAFE standard, 2025 (Partial undervaluation scenario)

\begin{tabular}{|c|c|c|c|c|c|c|}
\hline & \multicolumn{3}{|c|}{ Footprint standards } & \multicolumn{3}{|c|}{ Dual (car/truck) standards } \\
\hline & Base & CAFE & $\begin{array}{r}\text { CAFE } \\
\text { impact } \\
\end{array}$ & Base & CAFE & $\begin{array}{r}\text { CAFE } \\
\text { impact } \\
\end{array}$ \\
\hline $\begin{array}{l}\text { Average new-vehicle fuel economy } \\
\text { (mi/gal): }\end{array}$ & & & (\% diff.) & & & (\% diff.) \\
\hline All light-duty vehicles & 38.9 & 48.8 & $25.4 \%$ & 38.9 & 48.9 & $25.8 \%$ \\
\hline Conventional gasoline car & 37.0 & 43.9 & $18.7 \%$ & 37.0 & 44.1 & $19.1 \%$ \\
\hline Conventional gasoline truck & 31.2 & 34.9 & $11.7 \%$ & 31.2 & 34.5 & $10.6 \%$ \\
\hline Sales share by vehicle type: & & & (diff in $\%$ pts) & & & (diff in $\% \mathrm{pts})$ \\
\hline Conventional gasoline & $55.3 \%$ & $41.5 \%$ & $-13.8 \%$ & $55.3 \%$ & $40.5 \%$ & $-14.8 \%$ \\
\hline Diesel & $3.0 \%$ & $2.6 \%$ & $-0.3 \%$ & $3.0 \%$ & $2.7 \%$ & $-0.2 \%$ \\
\hline Hybrids (excl. plug-ins) & $17.5 \%$ & $27.7 \%$ & $10.2 \%$ & $17.5 \%$ & $30.4 \%$ & $12.8 \%$ \\
\hline Plugin hybrids + dedicated electric & $7.3 \%$ & $15.7 \%$ & $8.4 \%$ & $7.3 \%$ & $15.0 \%$ & $7.7 \%$ \\
\hline \multicolumn{7}{|l|}{ Sales share by technology used: } \\
\hline Micro hybrid (engine off at idle) & $19.1 \%$ & $48.9 \%$ & $29.7 \%$ & $19.1 \%$ & $46.7 \%$ & $27.6 \%$ \\
\hline Material subst'n (most advanced) & $1.4 \%$ & $31.6 \%$ & $30.3 \%$ & $1.4 \%$ & $32.5 \%$ & $31.1 \%$ \\
\hline
\end{tabular}


Table 12. Effects of dual CAFE standard on vehicle mix, 2025 (Partial undervaluation scenario)

\begin{tabular}{|c|c|c|c|c|c|c|}
\hline & \multicolumn{3}{|c|}{ Footprint standards } & \multicolumn{3}{|c|}{ Dual (car/truck) standards } \\
\hline & Base & CAFE & $\begin{array}{l}\text { CAFE } \\
\text { impact }\end{array}$ & Base & CAFE & $\begin{array}{l}\text { CAFE } \\
\text { impact } \\
\end{array}$ \\
\hline $\begin{array}{l}\text { Sales share by size class: non-fleet } \\
\text { vehicles }\end{array}$ & & & (\%-pt. diff.) & & & (\%-pt. diff.) \\
\hline \multicolumn{7}{|l|}{ Car } \\
\hline Minicompact & $1.3 \%$ & $1.3 \%$ & $0.0 \%$ & $1.3 \%$ & $1.4 \%$ & $0.0 \%$ \\
\hline Subcompact & $22.8 \%$ & $22.9 \%$ & $0.0 \%$ & $22.8 \%$ & $22.9 \%$ & $0.0 \%$ \\
\hline Compact & $19.5 \%$ & $19.4 \%$ & $0.0 \%$ & $19.5 \%$ & $19.9 \%$ & $0.4 \%$ \\
\hline Midsize & $33.2 \%$ & $33.2 \%$ & $0.0 \%$ & $33.2 \%$ & $33.0 \%$ & $-0.2 \%$ \\
\hline Large & $20.0 \%$ & $20.0 \%$ & $0.0 \%$ & $20.0 \%$ & $19.7 \%$ & $-0.3 \%$ \\
\hline Two Seater & $3.1 \%$ & $3.1 \%$ & $0.0 \%$ & $3.1 \%$ & $3.2 \%$ & $0.0 \%$ \\
\hline \multicolumn{7}{|l|}{ Truck } \\
\hline Small Pickup & $4.5 \%$ & $4.3 \%$ & $-0.2 \%$ & $4.5 \%$ & $4.1 \%$ & $-0.4 \%$ \\
\hline Large Pickup & $21.3 \%$ & $21.1 \%$ & $-0.2 \%$ & $21.3 \%$ & $22.3 \%$ & $1.0 \%$ \\
\hline Small Van & $1.8 \%$ & $1.8 \%$ & $0.0 \%$ & $1.8 \%$ & $1.7 \%$ & $-0.1 \%$ \\
\hline Large Van & $9.5 \%$ & $9.4 \%$ & $-0.1 \%$ & $9.5 \%$ & $9.1 \%$ & $-0.5 \%$ \\
\hline Small Utility & $34.2 \%$ & $34.6 \%$ & $0.3 \%$ & $34.2 \%$ & $34.1 \%$ & $-0.1 \%$ \\
\hline Large Utility & $28.6 \%$ & $28.8 \%$ & $0.2 \%$ & $28.6 \%$ & $28.7 \%$ & $0.1 \%$ \\
\hline
\end{tabular}

The effects on size mix are slightly larger if we start with the "severe undervaluation" case, but still not very large. These are shown in Appendix B, Table 12a. This insensitivity occurs despite the fact that in that scenario, price responses with any CAFE standard in place are enormous, amounting to charging a premium in year 2025 of over $\$ 4,600$ for a conventional midsize car and a discount of over $\$ 1,700$ on a hybrid small SUV (Table 13). The model predicts that such price incentives affect fuel type much more than size mix, mainly causing a large migration to hybrids and electric vehicles. 
Table 13. Effects of dual CAFE standard on price markups 2025 (Severe Undervaluation scenario)

\begin{tabular}{|c|c|c|c|c|c|c|}
\hline & \multicolumn{3}{|c|}{ Footprint Standards } & \multicolumn{3}{|c|}{ Dual (Car/Truck) Standards } \\
\hline & Base & CAFE & $\begin{array}{c}\text { CAFE } \\
\text { impact }\end{array}$ & Base & CAFE & $\begin{array}{c}\text { CAFE } \\
\text { impact }\end{array}$ \\
\hline Vehicle price markup (2009\$): & & & $\begin{array}{c}\text { (\% of base- } \\
\text { case cost) }\end{array}$ & & & $\begin{array}{c}(\% \text { of base- } \\
\text { case cost) }\end{array}$ \\
\hline Midsize car (conv gasoline) & 0 & 4,199 & $15.2 \%$ & 0 & 4,621 & $16.7 \%$ \\
\hline Small SUV (conv gasoline) & 0 & 2,695 & $10.8 \%$ & 0 & 895 & $3.6 \%$ \\
\hline Midsize car (gas-elec hybrid)) & 0 & -762 & $-2.3 \%$ & 0 & -507 & $-1.5 \%$ \\
\hline Small SUV (gas-elec hybrid)) & 0 & $-2,007$ & $-6.4 \%$ & 0 & $-1,714$ & $-5.5 \%$ \\
\hline
\end{tabular}

This lack of a significant size response is consistent with several other studies, although at odds with the predictions of empirical models from industrial organization. At this point I am unable to definitively state whether such a small effect on vehicle size mix is indeed a feature of automobile markets, or is due to something lacking in the way NEMS models them.

\subsection{Impacts on manufacturing and fuel costs}

This subsection assesses the effects of CAFE policies on two metrics that are part of a social welfare calculation, under the various scenarios considered in previous sections. The metrics are the change in the average manufacturing cost of a new car, and the change in fuel cost per 1000 miles traveled. The Regulatory Impact Analysis of these same standards (NHTSA 2012) suggests that these two (offsetting) factors play the dominant role in calculations of total costs and benefits of the policies.

I do not attempt to compute total welfare, however, because there are too many unknown factors in the path between these metrics and a social welfare calculation: it would be subject to large potential error, considering that net welfare involves large and partially offsetting effects. In addition, total costs and benefits would require discounting, introducing yet another source of uncertainty: namely, the appropriate discount factor. ${ }^{35}$ Nevertheless, the comparisons across

\footnotetext{
${ }^{35}$ Note that discounting affects the cost savings from greater fuel efficiency much more than the extra cost of new vehicles, because the savings are realized gradually over a longer time period. Thus the higher the discount rate, the more will the extra cost of vehicles tend to overshadow the fuel-cost savings.
} 
scenarios that presented here should give a good indication of the relative importance of the uncertainties that have been quantified here. ${ }^{36}$

Change in the average manufacturing cost of a new car. NEMS tracks the technologies used for each vehicle type and size, along with a calculation of its cost and consequences for fuel efficiency. In addition, consumers change their purchases of alternative-fueled vehicles in response to the CAFE policy, for example by purchasing more gasoline-electric hybrids, and to a much lesser extent more purely electric cars and more diesel cars. Both changes result in higher vehicle manufacturing costs. Our first metric is the aggregate of such extra costs over the 16-year period during which the simulated policy change is primarily active (2020-2035), divided by the total number of vehicles produced during that period under the CAFE policy. ${ }^{37}$

Change in fuel cost per 1000 miles traveled. This is the cost savings due to higher fuel efficiency ${ }^{38}$ divided by total post-policy vehicle-miles traveled (VMT) by all vehicles (not just those purchased under the new standards). Thus, the metric is an indicator of policy impact on all travelers through reducing their average cost of travel. The cost savings are calculated at pre-tax fuel prices, and thus represent a saving in social cost (but not including externalities related to carbon emissions or

\footnotetext{
${ }^{36}$ I do not estimate the environmental or petroleum-related benefits of the policy, which of course are its primary purpose. This is both because I am interested in the net policy costs of achieving the goals of the policy (which may vary among proponents), and because the environmental benefits as estimated by NHTSA (2012) were in fact considerably smaller than either of the two components I am focusing on here.

${ }^{37}$ Approximations are used to estimate the size mix for each vehicle type, using information about which size classes are offered in the market for a given type. Specifically, the sixteen vehicle types distinguished by NEMS are grouped into eight: conventional gasoline, gas-electric hybrid, diesel, diesel-electric hybrid, 100-mile electric, ethanol flex-fuel, plug-in hybrid, and all other. For each alternative-fueled vehicle type (i.e., the seven groups of vehicle type other than conventional gasoline), and each broad size category (car or truck), I assume that the distribution across those size classes that are produced for that type is the same as the distribution of all light-duty vehicles across those same size
}

classes. Thus the sales of type $t$ in size category $s$ is approximated as $q(t, s)=D(t, s) Q(t) \frac{Q_{A}(s)}{\sum_{s^{\prime}} D\left(t, s^{\prime}\right) Q_{A}\left(s^{\prime}\right)}$, where $D$ is a dummy variable for whether vehicles were produced of type $t$ and size $s, Q(t)$ is total sales of type $t$ vehicles, $Q_{A}\left(s^{\prime}\right)$ is total sales of size $s^{\prime}$ vehicles, and the summation is over sizes within the same broad size category (car or truck).

${ }^{38}$ The cost savings are those actually realized over the lifetimes of vehicles subject to each standard, which are not necessarily equal to the savings accounted for by consumers when they purchased the vehicles. 
petroleum usage). To account for cars purchased near the end of the evaluation period (2035), the fuel savings for each car are projected over its expected lifetime of 15 years; VMT is projected similarly. ${ }^{39}$ The figures shown are aggregate total savings divided by aggregate VMT, with no discounting.

Comparisons among scenarios. To focus on the sensitivities revealed in earlier subsections, I highlight here two sources of variation in CAFE policy evaluation: namely, consumer valuation of fuel price savings and future oil prices.

Consumer valuation of fuel price savings. Table 14 shows the two metrics for three valuation ratios, spanning the rather large range of uncertainty identified earlier. The table shows that both metrics vary by a factor of about 2.5 between the full valuation and the severe undervaluation scenarios. Thus the net policy cost - whether positive or negative — is likely to be larger in magnitude when consumers are assumed to undervalue fuel savings.

Table 14. Evaluation metrics of increased CAFE standards: Alternate valuations of fuel savings

\begin{tabular}{|l|c|c|c|}
\hline & $\begin{array}{c}\text { Full valuation } \\
\mathbf{( 1 0 0 \% )}\end{array}$ & $\begin{array}{c}\text { Partial valuation } \\
\mathbf{( 8 0} \mathbf{)})\end{array}$ & $\begin{array}{c}\text { Severe undervalue } \\
\mathbf{( 3 0 \% )}\end{array}$ \\
\hline $\begin{array}{l}\text { Change in cost of average new vehicle (2010\$) } \\
\quad \text { (total 2020-2035, undiscounted) }\end{array}$ & 1,082 & 1,492 & 2,584 \\
$\begin{array}{l}\text { Change in fuel cost per } 1000 \text { miles by all } \\
\text { vehicles (2010\$) } \\
\text { (total 2020-2050, undiscounted) }\end{array}$ & -7.86 & -11.55 & -20.25 \\
\hline
\end{tabular}

\section{Oil price scenarios}

Table 15 shows similar results for the three alternate oil price scenarios, all assuming 80 percent valuation. (The middle column thus repeats the "partial valuation" scenario appearing in Table15.)

\footnotetext{
${ }^{39}$ Both projections simply assume that the relevant aggregate quantity (fuel savings or VMT) declines linearly over this 15 -year period to a value of zero.
} 
Table 15. Evaluation metrics of increased CAFE standards: Alternate oil price scenarios

\begin{tabular}{|c|c|c|c|}
\hline & Low Oil Price & $\begin{array}{c}\text { Reference Oil } \\
\text { Price }\end{array}$ & High Oil Price \\
\hline $\begin{array}{l}\text { Change in cost of average new vehicle (2010\$) } \\
\text { (total 2020-2035, undiscounted) }\end{array}$ & 2,995 & 1,492 & 785 \\
\hline $\begin{array}{l}\text { Change in fuel cost per } 1000 \text { miles by all } \\
\text { vehicles (2010\$) } \\
\text { (total 2020-2050, undiscounted) }\end{array}$ & -10.23 & -11.55 & -7.88 \\
\hline
\end{tabular}

The fuel cost savings are only modestly different across the scenarios, and in fact not monotonic: they are highest at the intermediate ("reference") price, not at either extreme. This is because the low oil price scenario produces a greater difference in fuel consumption but fuel savings are worth less per gallon; conversely for the high oil price scenario.

By contrast, the extra cost of producing cars varies greatly across these scenarios. By this measure, the CAFE policy is nearly four times as costly at low oil prices as at high oil prices. This is because at low prices, the policy is more tightly binding, meaning that much more is spent on new vehicles in order to achieve changes in efficiencies which, at higher oil prices, occur voluntarily. Note that this does not mean cars are more costly to produce at low than at high oil prices; but rather, more of the cost is attributable to CAFE.

As a result of these patterns, the higher CAFE policy will tend to have a much higher net cost (increased manufacturing costs less fuel price savings) if oil prices are lower than expected, because the more expensive cars it requires will have only a modest payoff in fuel cost savings. Of course the environmental benefits, in terms of reduced $\mathrm{CO} 2$ emissions, will be highest in that scenario, so one cannot say from these observations which oil prices would most favor a tight CAFE policy in a full welfare assessment.

\section{Conclusion}

Of the factors I have evaluated, the two with greatest impacts on CAFE evaluation are consumers' fuel-cost valuations as reflected in manufacturers' decisions (i.e., the extent of an "energy paradox"), and the course of oil prices. A great deal of research has already gone into both topics, so I suspect they reflect irreducible uncertainties rather than uncertainties that can be 
significantly narrowed through more research. If this is correct, policy evaluation must simply accept the resulting uncertainty in policy impacts. The sensitivity with respect to future oil prices is especially daunting because those prices greatly affect the manufacturing costs incurred in meeting a CAFE standard, but have a much smaller effect on the offsetting savings in fuel expenditures realized by consumers. Thus, the net cost of the policy is quite uncertain, as is the size of its desired impacts on carbon emissions and fossil-fuel consumption.

Some other factors that might seem important are less so, according to the modeling reported here: price expectations, how the standard varies by vehicle size, and the magnitude of fines. This finding could be subject to revision if better ways are found to model these three factors.

We find it is very import to properly incorporate manufacturers' pricing responses to CAFE policies in order to accurately predict those policies' impacts. If manufacturers are unrealistically assumed to always price at production cost plus normal profit, policy evaluation will miss the significant changes in market shares that manufacturers will induce through various price markups and discounts. It is urgent for modelers to incorporate such responses where they currently do not. It would also be beneficial to develop more sophisticated models in which the oligopolistic rivalry among manufacturers, their medium-term and long-term planning requirements, and their marketing strategies are more fully recognized.

Given the results of this study, it is entirely possible that a simpler model than NEMS would be adequate to capture the most important effects of CAFE policies. Thus there is still room for limited purpose models that focus on one aspect, such as vehicle size mix or used-vehicle markets. Yet there is room as well for continued large-scale modeling of the type exemplified by NEMS, if only to identify which factors are important to understand various other energy policies that are also under consideration. 


\section{References}

Akerlof, George A. (1970). "The Market for 'Lemons': Quality Uncertainty and the Market Mechanism". Quarterly Journal of Economics, 84 (3): 488-500.

Allcott, Hunt (2013). "The Welfare Effects of Misperceived Product Costs: Data and Calibrations from the Automobile Market," American Economic Journal: Economic Policy, 5(3): 30-66.

Allcott, Hunt, and Michael Greenstone (2012), “Is there an energy efficiency gap?" Journal of Economic Perspectives, 26(1): 3-28.

Allcott, Hunt, and Nathan Wozny (2014), "Gasoline Prices, Fuel Economy, and the Energy Paradox," Review of Economics and Statistics, 96(5): 779-795.

Anderson, Soren T., Ryan Kellogg, and James M. Sallee (2013), "What Do Consumers Believe About Future Gasoline Prices?" Journal of Environmental Economics and Management, 66(3): 383-403.

Anderson, Soren T., Ian W.H. Parry, James M. Sallee, and Carolyn Fischer (2011), “Automobile Fuel Efficiency Standards: Impacts, Efficiency, and Alternatives," Review of Environmental Economics and Policy, 5(1): 89-108.

Anderson, Soren T., and James M. Sallee (2011), "Using Loopholes to Reveal the Marginal Cost of Regulation: The Case of Fuel-Economy Standards." American Economic Review, 101(4): 13751409.

Bento, Antonio, Kevin Roth, and Yiou Zuo (2018) "Vehicle Lifetime Trends and Scrappage Behavior in the U.S. Used Car Market," Energy Journal, 39(1).

Berry, Steven, James Levinsohn, and Ariel Pakes (1995), "Automobile Prices in Market Equilibrium," Econometrica, 63(4): 841-890.

Busse, Meghan R., Christopher R. Knittel, and Florian Zettelmeyer (2013), “Are Consumers Myopic? Evidence from New and Used Car Purchases," American Economic Review, 103(1): 220256.

Davis, Stacy C., Susan W. Diegel, and Robert G. Boundy (2012), Transportation Energy Data Book: Edition 31, Oak Ridge, Tennessee: Oak Ridge National Laboratory, July.

EIA (2011), Annual Energy Outlook 2011 With Projections to 2035, U.S. Energy Information Administration, U.S. Department of Energy, April. http://www.eia.gov/forecasts/archive/aeo11/pdf/0383(2011).pdf

EIA (2012), Transportation Sector Module of the National Energy Modeling System: Model Documentation. http://www.eia.gov/forecasts/nemsdoc/transportation/pdf/m070(2012).pdf 
EIA (2013), "Transportation Demand," in: Assumptions to AEO2013, pp. 73-98. http://www.eia.gov/forecasts/aeo/assumptions/index.cfm

Gerarden, Todd D., Richard G. Newell, and Robert N. Stavins (forthcoming) "Assessing the energy-efficiency gap," Journal of Economic Literature.

Gillingham, Kenneth, and Karen Palmer (2014), "Bridging the Energy Efficiency Gap: Policy Insights from Economic Theory and Empirical Evidence," Review of Environmental Economics and Policy, 8(1): pp. 18-38.

Goldberg, Pinelopi K. (1995), "Product Differentiation and Oligopoly in International Markets: The Case of the U.S. Automobile Industry," Econometrica, 63(4): 891-951.

Jacobsen, Mark R. (2013), "Evaluating US Fuel Economy Standards In a Model with Producer and Household Heterogeneity," American Economic Journal: Economic Policy, 5(2): 148-187.

Jacobsen, Mark R., and Arthur A. van Benthem (2015), "Vehicle Scrappage and Gasoline Policy," American Economic Review, 105(3): 1312-1338.

Knittel, Christopher R. (2012), "Reducing Petroleum Consumption from Transportation," Journal of Economic Perspectives, 26(1): 93-118.

Knittel, Christopher R. (2013), "Transportation Fuels Policy since the OPEC Embargo: Paved with Good Intentions" American Economic Review Papers and Proceedings, 103(3): 344-349.

Larrick, R. and J. Soll (2008), “The MPG Illusion,” Science 320 (5883), 1593-1594.

NHTSA (National Highway Traffic Safety Administration) (2012), Corporate Average Fuel Economy for MY 2017-MY 2025 Passenger Cars and Light Trucks: Final Regulatory Impact Analysis, August. www.nhtsa.gov/staticfiles/rulemaking/pdf/cafe/FRIA_2017-2025.pdf

Sallee, James M., Sarah E. West, and Wei Fan (2016), "Do consumers recognize the value of fuel economy? Evidence from used car prices and gasoline price fluctuations," Journal of Public Economics, 135: 61-73.

Small, Kenneth A. (2010), "Energy Policies for Automobile Transportation: A Comparison Using the National Energy Modeling System," Background report for Toward a New National Energy Policy: Assessing the Options, Resources for the Future and National Energy Policy Institute, June. http://www.rff.org/Documents/Features/NEPI/RFF-BCK-Small-AutoPolicies.pdf

Small, Kenneth A. (2012), "Energy Policies for Passenger Motor Vehicles," Transportation Research Part A: Policy and Practice, 46(6): 874-889.

Turrentine, Thomas S., and Kenneth S. Kurani (2007), “Car buyers and fuel economy?” Energy Policy, 35: 1213-1223. 
Whitefoot, Kate S., Meredith Fowlie, and Steven J. Skerlos (2013) "Compliance by design: Industry response to energy efficiency standards," Working paper, Carnegie Mellon University. https://scholar.google.com/citations?view_op=view_citation\&hl=en\&user=3W2VK5sAAAAJ\&cit ation_for_view=3W2VK5sAAAAJ:UeHWp8X0CEIC 


\section{Appendix A: Modifications of NEMS}

\section{A.1 Adding price responsiveness for manufacturers}

\section{$\underline{\text { Profit maximizing with elastic demand }}$}

Suppose a firm faces a demand curve for a product with elasticity $\eta<0$ and production cost $C(q)$ as a function of output $q$. It is choosing a price $p$ at which to sell its output.

To maximize profits, it chooses $q$ to maximize:

$$
\Pi=p q-C(q)
$$

First-order maximization condition:

$$
0=p+q \frac{d p}{d q}-C^{\prime}
$$

Denote marginal cost $C^{\prime}$ by $m c$, and note that $(q p / q) d q / d p=\eta$. Then

$$
\frac{p-C^{\prime}}{p}=\frac{1}{|\eta|}
$$

or equivalently,

$$
p=C^{\prime} \cdot \mu, \quad \quad \quad \text { where } \quad \mu=\left(\frac{1}{1-\frac{1}{|\eta|}}\right)=\frac{|\eta|}{|\eta|-1} .
$$

The term $\mu$ is the fractional markup. Note that this solution (in either form) is valid only if $|\eta|>1$ (assuming $m c>0$ ).

The equation is modified if the firm produces several products with interacting demands; then, the cross-elasticities of demand also enter the equation determining the markup. Here for simplicity I assume those cross-elasticities are zero.

\section{$\underline{\text { Profit maximization to meet a CAFE constraint (single standard) }}$}

Suppose for simplicity that the firm produces just two products, with no cross-elasticity. Now impose an average efficiency constraint for the two products, so the firm has to maximize 


$$
\Pi=p_{1} q_{1}+p_{2} q_{2}-C\left(q_{1}, q_{2}\right)
$$

subject to a constraint on the average fuel intensities $f_{1}, f_{2}$ of the two products:

$$
f_{1} q_{1}+f_{2} q_{2} \leq \bar{f} \cdot\left(q_{1}+q_{2}\right)
$$

where $\bar{f}$ is the inverse of the CAFE standard. The solution is found by maximizing the Lagrangian function:

$$
\Pi=p_{1} q_{1}+p_{2} q_{2}-C\left(q_{1}, q_{2}\right)+\lambda \cdot\left[\left(\bar{f}-f_{1}\right) q_{1}+\left(\bar{f}-f_{2}\right) q_{2}\right] .
$$

The first-order condition for each product is:

$$
0=p_{i}+q_{i} \frac{d p_{i}}{d q_{i}}-C_{i}+\lambda \cdot\left(\bar{f}-f_{i}\right)
$$

where $C_{i} \equiv \partial C / \partial q_{i}$ is the marginal cost of product $i$. This can be written as:

$$
\frac{p_{i}-C_{i}^{\prime}}{p_{i}}=\frac{1}{\left|\eta_{i}\right|}+\lambda \frac{\left(f_{i}-\bar{f}\right)}{p_{i}}
$$

or, to solve explicitly for $p_{i}$ :

$$
p_{i}=\left[C_{i}^{\prime}+\lambda \cdot\left(f_{i}-\bar{f}\right)\right] \cdot \mu_{i}
$$

where $\mu_{i}$ is defined analogously to (A1).

The term $\mu_{i}$ is a product-specific markup factor. The Lagrangian multiplier $\lambda$ is the shadow price of fuel efficiency, indicating that an additional price $\lambda \cdot\left(f_{i}-\bar{f}\right)$ is added to a vehicle with fuel intensity $f_{i}$, before applying the markup.)

One can argue that the initially observed prices already account for the product-specific markup, $\mu_{i}$. Marginal costs embedded in NEMS also account for $\mu_{i}$ insofar as the overhead added to the engineering cost is meant to cover this, although it may be an average markup $\bar{\mu}$ rather than an individual markup $\mu_{i}$. Therefore, the shadow price that we measure is really not $\lambda$ but $\lambda \mu_{i}$ (at least approximately), and the observed marginal costs in the model can be interpreted as $m c_{i} \equiv c_{i}^{\prime} \cdot \mu_{i}$. Then (A4) becomes:

$$
p_{i}=m c_{i}+\lambda \mu_{i} \cdot\left(f_{i}-\bar{f}\right) \text {. }
$$


We can determine $\lambda \mu_{i}$ iteratively by simulating a feebate policy (instead of CAFE) that is just stringent enough to cause the stated CAFE standard to be met.

\section{$\underline{\text { Footprint based standards }}$}

Now suppose there is a different standard for each product, but the firm is allowed to trade across products - which is now the case for footprint-based standards. The constraint is that the firm's fleet average has to be at least as efficient as the sales-weighted average of the product-specific intensity standards, $\bar{f}_{i}$ :

$$
f_{1} q_{1}+f_{2} q_{2} \leq \bar{f}_{1} q_{1}+\bar{f}_{2} q_{2}
$$

The first-order condition is modified to:

$$
0=p_{i}+q_{i} \frac{d p_{i}}{d q_{i}}-C_{i}+\lambda \cdot\left(\bar{f}_{i}-f_{i}\right)
$$

which yields

$$
\frac{p_{i}-m c_{i}}{p_{i}}=\frac{1}{\left|\eta_{i}\right|}+\lambda \frac{\left(f_{i}-\bar{f}_{i}\right)}{p_{i}}
$$

or equivalently,

$$
p_{i}=\left[m c_{i}+\lambda \cdot\left(f_{i}-\bar{f}_{i}\right)\right] \cdot \mu_{i}
$$

So the shadow prices of the different vehicles are now much closer to each other because they depend on deviations of $f_{i}$ from $\bar{f}_{i}$ instead of from a single value $\bar{f}$. In fact, if the solution were for each product to just meet its standard, the shadow price applied to the vehicle, $\lambda \cdot\left(f_{i}-\bar{f}_{i}\right)$, would be zero and we would be back to the single-product solution (A1) for each product. But this is unlikely to happen because it will usually be cheaper to improve fuel efficiency in some vehicles than others. For example, if manufacturers find it cheaper to improve fuel efficiency in product 1 than in product 2 , they will choose to make $f_{1}<\bar{f}_{1}$ (more than meet the standard for product 1) and $f_{2}>\bar{f}_{2}$; in that case they will also lower the price of vehicle 1 and raise the price of vehicle 2, by amounts that include the markup. This of course is to help them meet the standard by changing the mix of vehicles toward those that are easier to make efficient. The price differential between them will then be changed by an amount that depends on both markup factors: 


$$
\Delta p \equiv p_{2}-p_{1}=\Delta m c+\lambda \cdot\left[\left(f_{2}-\bar{f}_{2}\right) \mu_{2}-\left(f_{1}-\bar{f}_{1}\right) \mu_{1}\right]
$$

\section{Choice of fuel intensity (i.e., technology)}

Suppose unit costs are functions of fuel intensities $f_{i}$, and so are the prices at which consumers would choose the same quantities. We can represent this as demands

$$
q_{i}=d_{i}\left[p_{i}+\phi_{i}\left(f_{i}\right)\right]
$$

where $d_{i}(\cdot)$ is a demand function for product $i$. For simplicity I assume the cost function is linear in quantities, with coefficients $c_{i}$ that fall with fuel intensity:

$$
C\left(q_{1}, f_{1}, q_{2}, f_{2}\right)=q_{1} c_{1}\left(f_{1}\right)+q_{2} c_{2}\left(f_{2}\right) .
$$

Note that we expect $\phi_{i}^{\prime}>0$ and $c_{i}^{\prime}<0$. Invert the demand function to get each price as a function of quantity and fuel intensity:

$$
p_{i}=d_{i}^{-1}\left(q_{i}\right)-\phi_{i}\left(f_{i}\right)
$$

Note that $\phi_{i}\left(f_{i}\right)$ is represented in NEMS as a calculation in the manufacturers' vehicle choice submodule, in which the manufacturer assumes certain parameters for how consumers value future fuel savings: in the case of the default parameters, savings are projected from a 5-year past rolling average, valued for three years in the future, and discounted at rate $15 \%$.

Without CAFE:

The profit-maximizing condition for choosing fuel intensity with no CAFE is then to maximize:

$$
\Pi=q_{1} \cdot\left[d_{1}^{-1}\left(q_{1}\right)-\phi_{1}\left(f_{1}\right)\right]+q_{2} \cdot\left[d_{2}^{-1}\left(q_{2}\right)-\phi_{2}\left(f_{2}\right)\right]-q_{1} c_{1}\left(f_{1}\right)-q_{2} c_{2}\left(f_{2}\right)
$$

The first-order condition for choosing $f_{i}$ is:

$$
0=-q_{i} \phi_{i}^{\prime}-q_{i} c_{i}^{\prime}
$$

or

$$
-c_{i}^{\prime}=\phi_{i}^{\prime}
$$


This is approximately how NEMS represents the decision in in the manufacturers' technology choice submodule: manufacturers add technology so long as the cost of doing so $\left(-c_{i}^{\prime}\right)$ is no greater than its value to consumers $\left(\phi_{i}^{\prime}\right)$. (NEMS differs in one important detail, however, as described in Section A.3).

With CAFE (single standard):

Now add constraint (A2). The first-order condition now includes the effects of the Lagrangian, as follows:

$$
0=-q_{i} \phi_{i}^{\prime}-q_{i} c_{i}^{\prime}-\lambda q_{i}
$$

or

$$
c_{i}^{\prime}=\phi_{i}^{\prime}+\lambda
$$

So consumers' valuation of fuel economy is augmented by the same "shadow price of fuel intensity" as we observed in the pricing equations, $\lambda$. This is just like I modified NEMS in earlier work (Small 2012) to handle feebates; hence $\lambda$ can be extracted from that calculation, already programmed.

With CAFE (footprint-based standard):

Now the constraint is (A5), but the first-order condition is the same, leading again to condition (A8).

Fines in lieu of compliance:

If a manufacturer has the option of paying a fine $\bar{\lambda}$ per unit of fuel intensity by which it exceeds the standard $\bar{f}$, then the solution remains the same so when $\lambda \leq \bar{\lambda}$. When $\lambda$ would otherwise exceed $\bar{\lambda}$, the objection function becomes (A3) with $\lambda$ replaced by $\bar{\lambda}$. The first-order conditions for setting price and technology are again (A4) and (A8) but with $\lambda$ replaced by $\bar{\lambda}$. In other words, the overall solution is (A4) and (A8) with $\lambda$ capped at $\bar{\lambda}$.

The manufacturer may choose to comply even when its unit shadow cost of compliance exceeds $\bar{\lambda}$ if it perceives additional benefits, such as political or public-relations benefits, of compliance. This may lead to solution (A4) and (A8) even when $\lambda$ exceeds $\bar{\lambda}$. When $\lambda$ is high enough, the benefits of compliance will no longer exceed the costs and the solution will revert to one with an implicit fine. Whether that fine will be the legal fine $\bar{\lambda}$ or some higher value depends on how the perceived benefits of compliance depend on the magnitude of non-compliance. I will assume it depends linearly on the deviation from mandated fuel efficiency, in which case such a situation can be approximated by assuming a level of fine larger than the legal level.

\section{Summary}


As so often happens in economics, even when a lack of pure competition distorts pricing, it does not distort choice of quality.

\section{Overall summary}

When CAFE is introduced, technology choice proceeds just as it does with a feebate: manufacturers set the marginal cost of reducing fuel intensity equal to consumers' valuation $\phi_{i}$ plus a shadow price $\lambda$ whose size reflects how tight the CAFE standard is.

Vehicle pricing with CAFE also takes $\lambda$ into account as follows. If there is a single standard, price differentials are introduced between different products with fuel-intensity differences $\Delta f$. If demands were infinitely elastic, the price differential between two vehicles (in addition to that caused by differences in production cost $m c$ ) would be $\lambda \Delta f$ for a single standard and $\lambda \cdot(\Delta f-\Delta \bar{f})$ for separate standards. But accounting for demand elasticities, the price differential is instead given by (A7). In the case of footprint-based standards, the terms $f_{i}-\bar{f}_{i}$ are likely to be small and so (A7) would not differ much from an equation that assumes the markups are all equal to one, in which case it may not be worth the trouble of programming equation (A7).

\section{A.2 Adjusting coefficients in type choice model}

\section{A.2.1 Vehicle cost and fuel cost coefficients}

Our three scenarios involving different valuations by consumers of fuel savings are defined by the assumed consumer tradeoffs between vehicle price and fuel costs, as embodied in the interest rate and time horizon used in the NEMS module determining whether vehicle manufacturers will add particular technologies to their vehicle models. But consumers also trade off capital and operating costs in their choice of vehicle type - that is, their choice among various engine and fuel types such as conventional gasoline, diesel, gas-electric hybrid, and all-electric vehicles. This choice is governed in NEMS by a logit model, which implicitly involves maximizing a random utility function whose systematic components include various vehicle characteristics.

The utility component in the vehicle type model that relates to total ownership cost is:

$$
U=\beta_{p m} p_{m}+\beta_{p v} p_{v} \equiv x+y
$$

where $p_{m} \equiv p_{f} / E$ is fuel cost per mile, $p_{f}$ and $p_{v}$ are fuel price and vehicle price, respectively, and $E$ is the efficiency of the car being considered for purchase. Define the effective capital recovery factor, $C R F^{e}$, as the multiplier on capital cost that equates the marginal utility of first-year operating cost to that of annualized capital cost: 


$$
\frac{\partial U}{\partial\left(p_{m} M_{1}\right)}=\frac{\partial U}{\partial\left(p_{v} \cdot C R F\right)} \Rightarrow \frac{x}{y}=\frac{p_{m} M_{1}}{p_{v} \cdot C R F} \Rightarrow \frac{\beta_{p m}}{\beta_{p v}}=\frac{M_{1}}{C R F^{e}}
$$

where $M_{1}$ is first-year mileage. If annual mileage and expected fuel prices were constant, $C R F^{e}$ would equal the conventionally defined capital recovery factor at interest rate $r$ and expected asset life $T$ :

$$
C R F(r, T)=\frac{1}{\sum_{t=1}^{T}(1+r)^{-t}}=\frac{r}{1-(1+r)^{-T}} .
$$

Accounting for changes in fuel price and annual vehicle mileage, it is instead the ratio of first-year fuel cost to present discounted value of future fuel costs, as described in Section 3.2 of the text. ${ }^{40}$ implies:

Let superscript 0 represent the default parameters in NEMS, so that equation (A10)

$$
\frac{x^{0}}{y^{0}}=\frac{p_{m} M_{1}}{p_{v} \cdot C R F^{e 0}}
$$

I henceforth omit the superscript $e$ on $C R F$.

Suppose we change $r$ and $T$ from their default values, $r^{0}$ and $T^{0}$, to some other values $r$ and $T$, thus changing the $C R F$ from $C R F\left(r^{0}, T^{0}\right)$ to $C R F(r, T)$. We want to know how to change parameters $\beta_{p m}$ and $\beta_{p v}$ to be consistent. To do so, I impose two conditions. First is the continued validity of their ratio as embodied in (A10):

$$
\frac{x / y}{x^{0} / y^{0}}=\frac{1}{R}
$$

where $R \equiv C R F / C R F^{0}$ is assumed to follow (A11):

$$
R=\frac{r}{r^{0}} \cdot \frac{1-\left(1+r^{0}\right)^{-T^{0}}}{1-(1+r)^{-T}}
$$

${ }^{40}$ If fuel cost grew at constant rate $g_{P f}$ and mileage declined at constant rate $g_{M},(\mathrm{~A} 10)$ would apply approximately with $r$ replaced by $r-g_{P f}+g_{M}$. 
Second is that the utility component (A9) remain unchanged, so that its relative importance compared to that of other attributes is unchanged. This implies

$$
x+y=x^{0}+y^{0}
$$

The solution to (A13) and (A14) is;

$$
\frac{\beta_{p m}}{\beta_{p m}^{0}} \equiv \frac{x}{x^{0}}=\frac{x^{0}+y^{0}}{x^{0}+R y^{0}} ; \quad \frac{\beta_{p v}}{\beta_{p v}^{0}} \equiv \frac{y}{y^{0}}=R \cdot \frac{x^{0}+y^{0}}{x^{0}+R y^{0}}
$$

To calculate (A15), we need to know all the components of $x^{0}$ and $y^{0}$ : namely, the initial values of the coefficients and the values of the variables they apply to ( $p_{m}$ and $p_{v}$ ). These vary by size class and year; for simplicity I choose average values for each size class over the years 2017-2025 (which are the years over which the CAFE standards are ramped up in the high CAFE policy simulated here). I calculate it for the values of the ratio $R$ corresponding to our five valuation scenarios; in each case, $R$ is simply the ratio of the valuation fraction for the "severe undervaluation" scenario (0.2946) to that in the scenario in question $(0.80$ or 1.00$)$. The values are:

Reference scenario (accurate valuation): $\boldsymbol{R}=\mathbf{0 . 2 9 4 6}$

Mild undervaluation: $\boldsymbol{R}=\mathbf{0 . 3 6 8 3}$

$60 \%$ valuation: $\mathbf{R}=\mathbf{0 . 6 5 4 7}$

$45 \%$ valuation: $\mathbf{R}=\mathbf{0 . 4 9 1 0}$

Severe undervaluation: $\boldsymbol{R}=\mathbf{1 . 0 0 0 0}$ (by definition)

\section{A.2.2 Other coefficients}

In order to calibrate correctly to observed 2010 sales shares of diesels, hybrids, and flexfuel vehicles, I adjust two other coefficients of the model - the alternative-specific constant for diesel vehicle and a coefficient indicating preference for vehicles already having a substantial market share. I describe here the adjustment for the full valuation scenario (our market scenario); the adjustment for the partial undervaluation scenario is done proportionally. ${ }^{41}$

Table A. 2 shows the sales shares for 2010 calculated by the model with its default parameters (i.e. those used in AEO 2011) and, in the market scenario, with adjustment of $\beta_{p m}$ and $\beta_{p v}$ as described in Section AA.1. The three most prominent differences are that the uncalibrated market scenario, compared to actual, understates the market share for conventional gasoline vehicles and overstates those for gasoline-electric hybrids and, especially, for diesels. It also

\footnotetext{
${ }^{41}$ For example, the full valuation scenario changes the valuation ratio by 0.7 (from 0.3 in the NEMS default to 1.0 ), whereas the partial undervaluation scenario changes the valuation ratio by 0.5 (from 0.3 to 0.8 ). Therefore in the partial undervaluation scenario I adjust the NEMS default parameters by 0.5 / 0.7 of the amount that I adjust them for the market scenario; and similarly for $60 \%$ and $45 \%$ valuations.
} 
slightly overstates the market share for flexible-fuel vehicles (i.e., those that can operate on either gasoline or ethanol).

Table A.2. Market shares (\%) predicted by modified NEMS for 2010, with adjustments only to $\beta_{p m}$ and $\beta_{p v}$

\begin{tabular}{lccc}
\hline & $\begin{array}{c}\text { Severe } \\
\text { undervaluation } \\
\text { scenario }^{\mathrm{a}}\end{array}$ & $\begin{array}{c}\text { Market } \\
\text { scenario } \\
\text { uncalibrated }\end{array}$ & $\begin{array}{c}\text { Market } \\
\text { scenario } \\
\text { recalibrated }\end{array}$ \\
\hline Conventional gasoline & 84.1 & 76.8 & 82.4 \\
Diesel & 2.0 & 7.1 & 2.2 \\
Hybrid & 2.5 & 3.9 & 2.4 \\
Flex-fuel & 11.3 & 12.1 & 12.9 \\
Other & 0.07 & 0.11 & 0.02 \\
Total & 100.0 & 100.0 & 100.0 \\
\hline${ }^{a}$ These 2010 shares are virtually identical to those in the AEO 2011 projection tables.
\end{tabular}

We know that EIA has set various other constants in the model to calibrate sales shares to the actual values shown in the first column of numbers in Table A.2. If in fact people value fuel savings fully, some of these constants must actually be different from those assumed by EIA. I choose two as the mostly likely to be important: the coefficient of "make and model availability," and the alternative-specific constant for diesel engines.

The first of these parameters governs the importance of the availability of a wide selection of makes and models of a given vehicle type. Thus, it penalizes vehicle types that are less available than are conventional gasoline vehicles, on the grounds that consumers lack sufficient choice or that they fear lack of wide availability of fuels, parts, or competent service. I adjust this coefficient upward by $66.7 \%$, except for flex-fuel vehicles. Our reasoning for excluding flex-fuel vehicles is that if people are indeed fully rational in their fuel valuation, then the low market share of diesels and hybrids likely indicates that people find low availability a bigger barrier than assumed by NEMS. However, I do not apply this adjustment to flex-fuel vehicles (i.e., they have their own distinct coefficient for make and model availability), for three reasons: their engines are virtually identical to gasoline engines, they are mostly used with gasoline rather than ethanol, and their sales share is heavily influenced by special CAFE credits under current law. Therefore, for flex-fuel vehicles consumers have little reason to worry about either fuel availability or service.

The other parameter I adjust is an alternative specific constant for diesel vehicles, which reflects any undesirable features relative to gasoline vehicles, such as the reputation for reliability, anticipated odor from fumes, or availability of extensive dealer service. In the NEMS default values, this constant is set in 2010 to a positive value (0.5) for cars and to a very small negative value $(-0.05)$ for trucks; the value then decreases over time for cars and increases over time for trucks. I found that a simple downward adjustment of 0.4 gives a good calibration, in particular bringing diesel share in 2010 somewhat below hybrid share, as seen in the actual sales figures.

The results of these two adjustment are shown in the last column of Table A.2. This calibration slightly understates conventional gasoline and overstates flex-fuel sales shares in 
2010 , but it is really the sum of these that is important to policy outcomes because flex-fuel vehicles are so similar to gasoline.

\section{A.3 Optimization in the Manufacturers' Technology Choice Component (MTCC)}

The Manufacturers' Technology Choice Component (MTCC) of NEMS depicts how manufacturers decide on whether to implement each of a long list of technologies on each of the size classes of cars and trucks it produces. The calculation compares the per-car cost of implementing the technology with the fuel-savings benefit realized by consumers (aggregated over the assumed time horizon and discounted at the assumed rate, all figured the consumer's assumed fuel-price expectation). If the cost is less than the benefit, the technology is adopted.

The adjustment in our modified NEMS involves the details of the this calculation. In standard NEMS, the cost of a technology is given as a parameter which is constant per unit of increase in fuel efficiency (miles per gallon, or mpg). This parameter is compared with the calculated benefit to consumers per unit increase in mpg. Suppose $E$ is the efficiency of a size class, $\Delta E$ is the change in fuel efficiency per vehicle caused by a particular technology, and $\Delta C$ is the per-vehicle cost of this technology. Then the per-vehicle cost for this size class is $\Delta C$, while the per-car annual benefit is $M \cdot P_{F} \cdot \Delta E$, where $M$ is the mileage driven in that year and $P_{F}$ is the consumer's expected fuel price. Expressed per unit of fuel efficiency, then, the comparison is between $\Delta C / \Delta E$ and $M \cdot P_{F}$, with the latter added and discounted over the number of years specified as the time horizon. Note that $M \cdot P_{F}$ and its aggregate over years are constant across all technologies within a given size class.

In NEMS, each technology cost is specified by a parameter giving the value of $\Delta C / \Delta E$, which I refer to here as the "unit technology cost".

When CAFE regulations apply, this setup conveniently allows the regulations to be taken into account by adding a shadow price of the regulation (called "regulatory cost" in NEMS) to the unit technology cost. This is what is depicted in Equation (A.8) above. Depending on a manufacturer's attitude toward being out of compliance, it may replace the regulatory cost by the per-unit fine in this calculation when the fine is smaller.

However, note that although NEMS calculates the shadow price in terms of fuel efficiency, equation (A.8) involves fuel intensity. This is because, although CAFE standards are described legally in terms of fuel efficiency (mpg), they are actually implemented in terms of fuel intensity (gallons per mile, or gpm). This is how the characteristics of different model cars or trucks are averaged across a manufacturers in calculating whether their average efficiency meets the standard.

Specifically, in the CAFE law, each manufacturer's compliance with CAFE is determined by the (sales-weighted) harmonic average of the mpg for all the vehicles it produces. This ensures that the computed average efficiency is in fact equal to total mileage divided by total fuel use. Taking the harmonic average of mpg involves taking the average gpm, then inverting it. Thus, if the manufacturer is trying to meet the CAFE standard, it is per-unit the cost of reducing gpm that must be equated across technologies. A manufacturer wanting to achieve that standard at lowest cost will need to consider the incremental cost of any changes to gpm in its various size classes and individual technologies, and equalize them.

I have therefore modified the MTCC module to use fuel intensity rather than fuel efficiency to compute the regulatory cost which is added to the consumer's benefit to determine 
whether or not it's worth installing a given technology on a given size class. The effect of this change is to increase the value to a manufacturer of adding a given fuel savings to a lowefficiency car relative to a high-efficiency car, compared to the standard version of NEMS.

What if the manufacturer instead plans to pay fines for noncompliance? The law describes the fines in terms of mpg (although they are not exactly linear in mpg). But that fine is applied to the deviation of the harmonic average of mpg from the specified fuel efficiency standard. Thus, just as in the case of meeting the standard, a manufacturer seeking to minimize its cost including fines paid must compare the cost of reducing fuel intensity (gpm) to the fine expressed in terms of $\$ / \mathrm{gpm}$. Therefore, in our modified NEMS, the regulatory fine is converted to one proportional to fuel intensity, using the CAFE standard itself as it applies to that manufacturer.

For both the technology cost and the regulatory cost, the conversion to proportionality with fuel intensity uses a first-order approximation in the deviation $\Delta F$ in fuel intensity between the achieved fuel intensity and the standard. Let $E$ be the standard in terms of fuel efficiency (mpg) and $F$ be the standard in terms of fuel intensity (gpm). Let $\Delta E$ and $\Delta F$ be deviations from the standard. The first-order approximation is $\Delta E=\Delta(1 / F) \approx-(1 / F)^{2} \Delta F=E^{2} \cdot(-\Delta F)$. For example, the default level of fine in 2011 was taken to be $\$ 50$ per unit of mpg. So the payment for the fine, $P$, is

$$
P=50 \Delta E
$$

But it can be expressed equivalently as

$$
P=-50 \cdot F^{2} \cdot(-\Delta F)
$$

where $F=1 / E$. Note the fine set at is initially expressed in units of $\$ /(\mathrm{mi} / \mathrm{gal})$, whereas it is now expressed in units of $\$ /(\mathrm{gal} / \mathrm{mi})$. But the calculations are equivalent (to first order in deviations $\Delta F / F)$, because they result in the same payment $P$.

Without this change, the manufacturer is modeled as inefficiently putting too much technology into improving high-mpg cars and not enough into improving low-mpg cars (from the manufacturer's own perspective). In other words, it treats the manufacturers as having the same "MPG illusion" that consumers have been found to have (Larrick, R. and J. Soll (2008), Allcott (2011). But actually it is inconceivable that manufacturers would have this illusion about such a basic fact of their business. 


\section{Appendix B. Other simulations}

Table 1a. Price of motor gasoline, selected years (2010 \$/gal)

\begin{tabular}{|l|c|c|c|c|c|}
\hline Scenario & $\mathbf{2 0 1 5}$ & $\mathbf{2 0 2 0}$ & $\mathbf{2 0 2 5}$ & $\mathbf{2 0 3 0}$ & $\mathbf{2 0 3 5}$ \\
\hline Low Oil Price & 2.19 & 2.33 & 2.14 & 2.26 & 2.16 \\
\hline Reference & 3.16 & 3.40 & 3.58 & 3.67 & 3.79 \\
\hline High Oil Price & 4.27 & 4.84 & 5.06 & 5.26 & 5.38 \\
\hline
\end{tabular}

Table 3a. Effects of price adjustments, 2025 (30\% valuation, High fines)

\begin{tabular}{|c|c|c|c|c|c|c|}
\hline & \multicolumn{3}{|c|}{ With price adjustments } & \multicolumn{3}{|c|}{ Without price adjustments } \\
\hline & Base & CAFE & $\begin{array}{r}\text { CAFE } \\
\text { impact } \\
\end{array}$ & Base & CAFE & $\begin{array}{r}\text { CAFE } \\
\text { impact }\end{array}$ \\
\hline $\begin{array}{l}\text { Average new-vehicle fuel economy } \\
\text { (mi/gal): }\end{array}$ & & & (\% diff.) & & & (\% diff.) \\
\hline All light-duty vehicles & 34.9 & 48.6 & $39.1 \%$ & 35.8 & 47.4 & $32.4 \%$ \\
\hline Conventional gasoline car & 35.5 & 39.0 & $10.0 \%$ & 36.3 & 49.0 & $35.2 \%$ \\
\hline Conventional gasoline truck & 27.4 & 31.9 & $16.4 \%$ & 28.0 & 37.6 & $34.5 \%$ \\
\hline Sales share by vehicle type: & & & (\%-pt diff) & & & (\%-pt diff) \\
\hline Conventional gasoline & $60.7 \%$ & $33.9 \%$ & $-26.8 \%$ & $60.3 \%$ & $59.6 \%$ & $-0.6 \%$ \\
\hline Diesel & $4.2 \%$ & $4.8 \%$ & $0.6 \%$ & $3.6 \%$ & $3.8 \%$ & $0.3 \%$ \\
\hline Hybrids (excl. plug-ins) & $11.9 \%$ & $31.3 \%$ & $19.4 \%$ & $12.4 \%$ & $13.2 \%$ & $0.7 \%$ \\
\hline Plugin hybrids + dedicated electric & $5.4 \%$ & $21.3 \%$ & $15.9 \%$ & $5.7 \%$ & $5.9 \%$ & $0.2 \%$ \\
\hline \multicolumn{7}{|l|}{ Sales share by technology used: } \\
\hline Micro hybrid (engine off at idle) & $5.9 \%$ & $16.4 \%$ & $10.5 \%$ & $9.2 \%$ & $61.4 \%$ & $52.3 \%$ \\
\hline Material subst'n (most advanced) & $0.5 \%$ & $6.0 \%$ & $5.5 \%$ & $0.4 \%$ & $64.0 \%$ & $63.6 \%$ \\
\hline
\end{tabular}


Table 3b. Effects of fuel price expectations, 2025 (80\% Valuation)

\begin{tabular}{|c|c|c|c|c|c|c|}
\hline & \multicolumn{3}{|c|}{ Default expectations } & \multicolumn{3}{|c|}{ Random walk } \\
\hline & Base & CAFE & \begin{tabular}{r|} 
CAFE \\
impact \\
\end{tabular} & Base & CAFE & $\begin{array}{r}\text { CAFE } \\
\text { impact } \\
\end{array}$ \\
\hline $\begin{array}{l}\text { Average new-vehicle fuel economy } \\
\text { (mi/gal): }\end{array}$ & & & (\% diff.) & & & (\% diff.) \\
\hline All light-duty vehicles & 38.9 & 48.8 & $25.4 \%$ & 38.6 & 48.8 & $26.4 \%$ \\
\hline Conventional gasoline car & 37.0 & 43.9 & $18.7 \%$ & 36.9 & 43.3 & $17.3 \%$ \\
\hline Conventional gasoline truck & 31.2 & 34.9 & $11.7 \%$ & 31.0 & 34.9 & $12.4 \%$ \\
\hline Sales share by vehicle type: & & & (diff in \% pts) & & & (diff in \% pts) \\
\hline Conventional gasoline & $55.3 \%$ & $41.5 \%$ & $-13.8 \%$ & $56.4 \%$ & $41.0 \%$ & $-15.3 \%$ \\
\hline Diesel & $3.0 \%$ & $2.6 \%$ & $-0.3 \%$ & $3.0 \%$ & $2.5 \%$ & $-0.4 \%$ \\
\hline Hybrids (excl. plug-ins) & $17.5 \%$ & $27.7 \%$ & $10.2 \%$ & $16.8 \%$ & $27.7 \%$ & $10.9 \%$ \\
\hline Plugin hybrids + dedicated electric & $7.3 \%$ & $15.7 \%$ & $8.4 \%$ & $7.0 \%$ & $16.3 \%$ & $9.3 \%$ \\
\hline \multicolumn{7}{|l|}{ Sales share by technology used: } \\
\hline Micro hybrid (engine off at idle) & $19.1 \%$ & $48.9 \%$ & $29.7 \%$ & $19.8 \%$ & $48.5 \%$ & $28.8 \%$ \\
\hline Material subst' $\mathrm{n}$ (most advanced) & $1.4 \%$ & $31.6 \%$ & $30.3 \%$ & $1.3 \%$ & $30.7 \%$ & $29.4 \%$ \\
\hline
\end{tabular}

Table 3c. Effects of fuel price expectations, 2025 (High oil price scenario)

\begin{tabular}{|c|c|c|c|c|c|c|}
\hline & \multicolumn{3}{|c|}{ Default Expectations } & \multicolumn{3}{|c|}{ Rational Expectations } \\
\hline & Base & CAFE & $\begin{array}{l}\text { CAFE } \\
\text { impact }\end{array}$ & Base & CAFE & $\begin{array}{l}\text { CAFE } \\
\text { impact }\end{array}$ \\
\hline $\begin{array}{l}\text { Average new-vehicle fuel economy } \\
\text { (mi/gal): }\end{array}$ & & & (\% diff.) & & & (\% diff.) \\
\hline All light-duty vehicles & 43.1 & 49.6 & $15.1 \%$ & 42.7 & 49.7 & $16.4 \%$ \\
\hline Conventional gasoline car & 39.7 & 45.1 & $13.6 \%$ & 39.0 & 44.5 & $14.1 \%$ \\
\hline Conventional gasoline truck & 34.7 & 36.9 & $6.4 \%$ & 34.4 & 36.9 & $7.3 \%$ \\
\hline Sales share by vehicle type: & & & (diff in \% pts) & & & iff in \% pts) \\
\hline Conventional gasoline & $40.9 \%$ & $37.6 \%$ & $-3.4 \%$ & $40.5 \%$ & $36.8 \%$ & $-3.7 \%$ \\
\hline Diesel & $3.8 \%$ & $3.7 \%$ & $-0.1 \%$ & $3.9 \%$ & $3.7 \%$ & $-0.2 \%$ \\
\hline Hybrids (excl. plug-ins) & $20.6 \%$ & $24.7 \%$ & $4.1 \%$ & $20.6 \%$ & $25.0 \%$ & $4.4 \%$ \\
\hline Plugin hybrids + dedicated electric & $9.8 \%$ & $14.5 \%$ & $4.7 \%$ & $9.8 \%$ & $15.2 \%$ & $5.3 \%$ \\
\hline Sales share by technology used: & & & & & & \\
\hline Micro hybrid (e & $36.9 \%$ & $57.3 \%$ & $20.5 \%$ & $35.0 \%$ & $57.3 \%$ & $22.2 \%$ \\
\hline Material subst'n (most advanced) & $5.2 \%$ & $35.5 \%$ & $30.4 \%$ & $4.7 \%$ & $35.7 \%$ & $30.9 \%$ \\
\hline
\end{tabular}


Table 3d. Effects of fuel price expectations, 2025 (30\% valuation)

\begin{tabular}{|c|c|c|c|c|c|c|}
\hline & \multicolumn{3}{|c|}{ Default expectations } & \multicolumn{3}{|c|}{ Random walk } \\
\hline & Base & CAFE & $\begin{array}{l}\text { CAFE } \\
\text { impact }\end{array}$ & Base & CAFE & $\begin{array}{c}\text { CAFE } \\
\text { impact }\end{array}$ \\
\hline $\begin{array}{l}\text { Average new-vehicle fuel economy } \\
\text { (mi/gal): }\end{array}$ & & & (\% diff.) & & & (\% diff.) \\
\hline All light-duty vehicles & 34.9 & 48.7 & $39.6 \%$ & 34.9 & 49.0 & $40.4 \%$ \\
\hline Conventional gasoline car & 35.5 & 39.1 & $10.3 \%$ & 35.6 & 39.6 & $11.4 \%$ \\
\hline Conventional gasoline truck & 27.4 & 32.0 & $16.8 \%$ & 27.4 & 32.0 & $16.7 \%$ \\
\hline Sales share by vehicle type: & & & (\%-pt diff) & & & (\%-pt diff) \\
\hline Conventional gasoline & $60.7 \%$ & $34.0 \%$ & $-26.8 \%$ & $60.2 \%$ & $33.9 \%$ & $-26.3 \%$ \\
\hline Diesel & $4.2 \%$ & $4.8 \%$ & $0.6 \%$ & $4.1 \%$ & $4.6 \%$ & $0.5 \%$ \\
\hline Hybrids (excl. plug-ins) & $11.9 \%$ & $31.2 \%$ & $19.3 \%$ & $11.9 \%$ & $31.1 \%$ & $19.2 \%$ \\
\hline Plugin hybrids + dedicated electric & $5.4 \%$ & $21.4 \%$ & $16.0 \%$ & $5.4 \%$ & $21.6 \%$ & $16.3 \%$ \\
\hline \multicolumn{7}{|l|}{ Sales share by technology used: } \\
\hline Micro hybrid (engine off at idle) & $5.9 \%$ & $16.8 \%$ & $10.9 \%$ & $6.6 \%$ & $18.1 \%$ & $11.4 \%$ \\
\hline Material subst'n (most advanced) & $0.5 \%$ & $6.3 \%$ & $5.7 \%$ & $0.5 \%$ & $7.5 \%$ & $7.0 \%$ \\
\hline
\end{tabular}


Table 4a. Effects of price adjustments on vehicle costs, 2025 (30\% valuation, High fines)

\begin{tabular}{|c|c|c|c|c|c|c|}
\hline & \multicolumn{3}{|c|}{ With price adjustments } & \multicolumn{3}{|c|}{ Without price adjustments } \\
\hline & Base & CAFE & $\begin{array}{r}\text { CAFE } \\
\text { impact }\end{array}$ & Base & CAFE & $\begin{array}{r}\text { CAFE } \\
\text { impact }\end{array}$ \\
\hline Vehicle cost (2010\$): & & & (\% diff.) & & & (\% diff.) \\
\hline Midsize car (conv gasoline) & 27,880 & 28,513 & $2.3 \%$ & 28,097 & 30,803 & $9.6 \%$ \\
\hline Small SUV (conv gasoline) & 25,076 & 26,070 & $4.0 \%$ & 25,207 & 27,708 & $9.9 \%$ \\
\hline Midsize car (gas-elec hybrid)) & 34,148 & 30,178 & $-11.6 \%$ & 34,246 & 36,194 & $5.7 \%$ \\
\hline Small SUV (gas-elec hybrid)) & 31,490 & 29,143 & $-7.5 \%$ & 31,536 & 32,803 & $4.0 \%$ \\
\hline Vehicle price markup (2010\$): & & & $\begin{array}{c}(\% \text { of base- } \\
\text { case cost) }\end{array}$ & & & $\begin{array}{c}(\% \text { of base- } \\
\text { case cost })\end{array}$ \\
\hline Midsize car (conv gasoline) & 0 & 4,248 & $15.2 \%$ & 0 & 0 & $\mathbf{0 . 0 \%}$ \\
\hline Small SUV (conv gasoline) & 0 & 2,753 & $11.0 \%$ & 0 & 0 & $0.0 \%$ \\
\hline Midsize car (gas-elec hybrid)) & 0 & -757 & $-2.2 \%$ & 0 & 0 & $0.0 \%$ \\
\hline Small SUV (gas-elec hybrid)) & 0 & $-2,006$ & $-6.4 \%$ & 0 & 0 & $0.0 \%$ \\
\hline $\begin{array}{l}\text { Fines paid in lieu of compliance } \\
\text { (\$/vehicle): }\end{array}$ & & & $\begin{array}{l}\text { (\% of base- } \\
\text { case price) }\end{array}$ & & & $\begin{array}{l}\text { (\% of base- } \\
\text { case price) }\end{array}$ \\
\hline Cars & 22 & 81 & $0.3 \%$ & 18 & 1,918 & $6.9 \%$ \\
\hline Trucks & 0 & 0 & $0.0 \%$ & 0 & 55 & $0.2 \%$ \\
\hline
\end{tabular}


Table 5a. Effects of full range of valuations, 2025

\begin{tabular}{|c|c|c|c|c|c|c|c|c|c|c|c|c|}
\hline & \multicolumn{3}{|c|}{ Full valuation $(\mathbf{1 0 0 \%})$} & \multicolumn{3}{|c|}{ Partial valuation $(80 \%)$} & \multicolumn{3}{|c|}{$60 \%$ valuation } & \multicolumn{3}{|c|}{ Severe undervalue $(30 \%)$} \\
\hline & Base & CAFE & $\begin{array}{r}\text { CAFE } \\
\text { impact } \\
\end{array}$ & Base & CAFE & $\begin{array}{l}\text { CAFE } \\
\text { impact }\end{array}$ & Base & CAFE & $\begin{array}{r}\text { CAFE } \\
\text { impact } \\
\end{array}$ & Base & CAFE & $\begin{array}{r}\text { CAFE } \\
\text { impact } \\
\end{array}$ \\
\hline $\begin{array}{l}\text { Average new-vehicle fuel economy } \\
\text { (mi/gal): }\end{array}$ & & & (\% diff.) & & & (\% diff.) & & & (\% diff.) & & & (\% diff.) \\
\hline All light-duty vehicles & 40.8 & 48.8 & $19.4 \%$ & 38.9 & 48.8 & $25.4 \%$ & 37.0 & 48.9 & $32.1 \%$ & 34.9 & 48.7 & $39.6 \%$ \\
\hline Conventional gasoline car & 38.2 & 44.9 & $17.4 \%$ & 37.0 & 43.9 & $18.7 \%$ & 36.0 & 42.6 & $18.3 \%$ & 35.5 & 39.1 & $10.3 \%$ \\
\hline Conventional gasoline truck & 32.8 & 34.8 & $6.0 \%$ & 31.2 & 34.9 & $11.7 \%$ & 29.6 & 34.3 & $15.8 \%$ & 27.4 & 32.0 & $16.8 \%$ \\
\hline Sales share by vehicle type: & & & (diff in \% pts) & & & iff in $\%$ pts) & & & (diff in \% pts) & & & (diff in \% pts) \\
\hline Conventional gasoline & $52.5 \%$ & $41.9 \%$ & $-10.6 \%$ & $55.3 \%$ & $41.5 \%$ & $-13.8 \%$ & $58.6 \%$ & $38.9 \%$ & $-19.7 \%$ & $60.7 \%$ & $34.0 \%$ & $-26.8 \%$ \\
\hline Diesel & $2.4 \%$ & $2.1 \%$ & $-0.3 \%$ & $3.0 \%$ & $2.6 \%$ & $-0.3 \%$ & $3.6 \%$ & $3.4 \%$ & $-0.3 \%$ & $4.2 \%$ & $4.8 \%$ & $0.6 \%$ \\
\hline Hybrids (excl. plug-ins) & $20.6 \%$ & $28.8 \%$ & $8.2 \%$ & $17.5 \%$ & $27.7 \%$ & $10.2 \%$ & $14.5 \%$ & $30.6 \%$ & $16.1 \%$ & $11.9 \%$ & $31.2 \%$ & $19.3 \%$ \\
\hline Plugin hybrids + dedicated electric & $7.9 \%$ & $14.3 \%$ & $6.5 \%$ & $7.3 \%$ & $15.7 \%$ & $8.4 \%$ & $6.2 \%$ & $16.4 \%$ & $10.2 \%$ & $5.4 \%$ & $21.4 \%$ & $16.0 \%$ \\
\hline Sales share by technology used: & & & & & & & & & & & & \\
\hline Micro hybrid (engine off at idle) & $29.7 \%$ & $52.6 \%$ & $22.9 \%$ & $19.1 \%$ & $48.9 \%$ & $29.7 \%$ & $10.9 \%$ & $35.5 \%$ & $24.6 \%$ & $5.9 \%$ & $16.8 \%$ & $10.9 \%$ \\
\hline Material subst' (most advanced) & $2.7 \%$ & $37.7 \%$ & $35.0 \%$ & $1.4 \%$ & $31.6 \%$ & $30.3 \%$ & $0.8 \%$ & $23.5 \%$ & $22.7 \%$ & $0.5 \%$ & $6.3 \%$ & $5.7 \%$ \\
\hline
\end{tabular}

Table 6a. Effects of full range of valuations on selected vehicle costs, 2025

\begin{tabular}{|c|c|c|c|c|c|c|c|c|c|c|c|c|}
\hline & \multicolumn{3}{|c|}{ Full valuation $(100 \%)$} & \multicolumn{3}{|c|}{ Partial valuation $(80 \%)$} & \multicolumn{3}{|c|}{$60 \%$ valuation } & \multicolumn{3}{|c|}{ Severe undervalue $(30 \%)$} \\
\hline & Base & CAFE & $\begin{array}{r}\text { CAFE } \\
\text { impact }\end{array}$ & Base & CAFE & $\begin{array}{r}\text { CAFE } \\
\text { impact } \\
\end{array}$ & Base & CAFE & $\begin{array}{r}\text { CAFE } \\
\text { impact } \\
\end{array}$ & Base & CAFE & $\begin{array}{r}\text { CAFE } \\
\text { impact } \\
\end{array}$ \\
\hline Vehicle cost (2010\$): & & & (\% diff.) & & & (\% diff.) & & & (\% diff.) & & & (\% diff.) \\
\hline Midsize car (conv gasoline) & 28,573 & 30,143 & $5.5 \%$ & 28,235 & 29,889 & $5.9 \%$ & 28,024 & 29,426 & $5.0 \%$ & 27,880 & 28,562 & $2.4 \%$ \\
\hline Small SUV (conv gasoline) & 26,443 & 27,135 & $2.6 \%$ & 25,941 & 27,103 & $4.5 \%$ & 25,473 & 26,445 & $3.8 \%$ & 25,076 & 26,107 & $4.1 \%$ \\
\hline Midsize car (gas-elec hybrid)) & 34,351 & 35,270 & $2.7 \%$ & 34,255 & 35,005 & $2.2 \%$ & 34,197 & 34,728 & $1.6 \%$ & 34,148 & 34,426 & $0.8 \%$ \\
\hline Small SUV (gas-elec hybrid)) & 31,470 & 31,885 & $1.3 \%$ & 31,449 & 32,005 & $1.8 \%$ & 31,479 & 31,889 & $1.3 \%$ & 31,490 & 31,885 & $1.3 \%$ \\
\hline Vehicle price markup (2010\$): & & & $\begin{array}{c}\text { (\% of cost in } \\
\text { base case) }\end{array}$ & & & $\begin{array}{c}\% \text { of cost in } \\
\text { base case })\end{array}$ & & & $\begin{array}{c}\% \text { of cost in } \\
\text { base case })\end{array}$ & & & $\begin{array}{l}\text { (\% of cost in } \\
\text { base case })\end{array}$ \\
\hline Midsize car (conv gasoline) & 0 & 1,323 & $4.6 \%$ & 0 & 1,726 & $6.1 \%$ & 0 & 2,719 & $9.7 \%$ & 0 & 4,199 & $15.1 \%$ \\
\hline Small SUV (conv gasoline) & 0 & 608 & $2.3 \%$ & 0 & 746 & $2.9 \%$ & 0 & 288 & $1.1 \%$ & 0 & 2,696 & $10.7 \%$ \\
\hline Midsize car (gas-elec hybrid)) & 0 & -907 & $-2.6 \%$ & 0 & -943 & $-2.8 \%$ & 0 & -838 & $-2.4 \%$ & 0 & -762 & $-2.2 \%$ \\
\hline Small SUV (gas-elec hybrid)) & 0 & -868 & $-2.8 \%$ & 0 & $-1,080$ & $-3.4 \%$ & 0 & -898 & $-2.9 \%$ & 0 & $-2,007$ & $-6.4 \%$ \\
\hline $\begin{array}{l}\text { Fines paid in lieu of compliance } \\
\text { (\$/vehicle): }\end{array}$ & & & $\begin{array}{l}\% \text { of price in } \\
\text { base case) }\end{array}$ & & & $\begin{array}{l}\text { (\% of price in } \\
\text { base case) }\end{array}$ & & & $\begin{array}{l}\text { (\% of price in } \\
\text { base case) }\end{array}$ & & & $\begin{array}{l}\text { (\% of price in } \\
\text { base case) }\end{array}$ \\
\hline
\end{tabular}


Table 12a. Effects of dual CAFE standard on vehicle size mix, 2025

(Severe undervalue scenario)

\begin{tabular}{|c|c|c|c|c|c|c|}
\hline & \multicolumn{3}{|c|}{ Footprint Standards } & \multicolumn{3}{|c|}{ Dual (Car/Truck) Standards } \\
\hline & Base & CAFE & $\begin{array}{c}\text { CAFE } \\
\text { impact }\end{array}$ & Base & CAFE & $\begin{array}{c}\text { CAFE } \\
\text { impact }\end{array}$ \\
\hline $\begin{array}{l}\text { Sales Shares by Size Class: Non-fleet } \\
\text { vehicles }\end{array}$ & & & (\%-pt. diff.) & & & (\%-pt. diff.) \\
\hline \multicolumn{7}{|l|}{ Car } \\
\hline Minicompact & $1.3 \%$ & $1.3 \%$ & $0.0 \%$ & $1.3 \%$ & $1.4 \%$ & $0.1 \%$ \\
\hline Subcompact & $22.8 \%$ & $23.0 \%$ & $0.2 \%$ & $22.8 \%$ & $23.0 \%$ & $0.1 \%$ \\
\hline Compact & $19.5 \%$ & $19.3 \%$ & $-0.1 \%$ & $19.5 \%$ & $20.1 \%$ & $0.7 \%$ \\
\hline Midsize & $33.2 \%$ & $33.2 \%$ & $0.0 \%$ & $33.2 \%$ & $32.9 \%$ & $-0.3 \%$ \\
\hline Large & $20.0 \%$ & $20.0 \%$ & $0.0 \%$ & $20.0 \%$ & $19.4 \%$ & $-0.7 \%$ \\
\hline Two Seater & $3.2 \%$ & $3.1 \%$ & $0.0 \%$ & $3.2 \%$ & $3.2 \%$ & $0.0 \%$ \\
\hline \multicolumn{7}{|l|}{ Truck } \\
\hline Small Pickup & $4.5 \%$ & $4.3 \%$ & $-0.3 \%$ & $4.5 \%$ & $4.0 \%$ & $-0.6 \%$ \\
\hline Large Pickup & $21.4 \%$ & $20.9 \%$ & $-0.4 \%$ & $21.4 \%$ & $23.0 \%$ & $1.6 \%$ \\
\hline Small Van & $1.8 \%$ & $1.7 \%$ & $-0.1 \%$ & $1.8 \%$ & $1.6 \%$ & $-0.2 \%$ \\
\hline Large Van & $9.6 \%$ & $9.2 \%$ & $-0.3 \%$ & $9.6 \%$ & $8.7 \%$ & $-0.9 \%$ \\
\hline Small SUV & $34.2 \%$ & $34.8 \%$ & $0.6 \%$ & $34.2 \%$ & $34.0 \%$ & $-0.1 \%$ \\
\hline Large SUV & $28.5 \%$ & $29.0 \%$ & $0.5 \%$ & $28.5 \%$ & $28.8 \%$ & $0.3 \%$ \\
\hline
\end{tabular}

